\title{
Atmosphere-only GCM (ACCESS1.0) simulations with prescribed land surface temperatures
}

\author{
Duncan Ackerley and Dietmar Dommenget \\ ARC Centre of Excellence for Climate System Science, School of Earth Atmosphere and Environment, Monash University, \\ Clayton 3800, Victoria, Australia \\ Correspondence to: Duncan Ackerley (duncan.ackerley@monash.edu)
}

Received: 11 January 2016 - Published in Geosci. Model Dev. Discuss.: 19 January 2016

Revised: 9 May 2016 - Accepted: 20 May 2016 - Published: 7 June 2016

\begin{abstract}
General circulation models (GCMs) are valuable tools for understanding how the global ocean-atmosphereland surface system interacts and are routinely evaluated relative to observational data sets. Conversely, observational data sets can also be used to constrain GCMs in order to identify systematic errors in their simulated climates. One such example is to prescribe sea surface temperatures (SSTs) such that $70 \%$ of the Earth's surface temperature field is observationally constrained (known as an Atmospheric Model Intercomparison Project, AMIP, simulation). Nevertheless, in such simulations, land surface temperatures are typically allowed to vary freely, and therefore any errors that develop over the land may affect the global circulation. In this study therefore, a method for prescribing the land surface temperatures within a GCM (the Australian Community Climate and Earth System Simulator, ACCESS) is presented. Simulations with this prescribed land surface temperature model produce a mean climate state that is comparable to a simulation with freely varying land temperatures; for example, the diurnal cycle of tropical convection is maintained. The model is then developed further to incorporate a selection of "proof of concept" sensitivity experiments where the land surface temperatures are changed globally and regionally. The resulting changes to the global circulation in these sensitivity experiments are found to be consistent with other idealized model experiments described in the wider scientific literature. Finally, a list of other potential applications is described at the end of the study to highlight the usefulness of such a model to the scientific community.
\end{abstract}

\section{Introduction}

In order to minimize circulation errors in general circulation models (GCMs), simulations with prescribed sea surface temperatures (SSTs) from past observations are used (for example between 1979 and 2008 as part of the Atmospheric Model Intercomparison Project - AMIP: Gates, 1992; Gates et al., 1999; Taylor et al., 2012). Nevertheless, the land surface temperatures are allowed to vary freely in response to the prescribed SST fields in AMIP simulations, which means biases in the representation of surface processes may lead to errors in the simulated atmospheric circulation. Such AMIP experiments have been developed further to include (amongst others) uniform increases of $4 \mathrm{~K}$ to the 1979-2008 SST data set and quadrupling carbon-dioxide concentrations with the 1979-2008 SST data (AMIP4K and AMIP4xCO 2 , respectively - Bony et al., 2011; Taylor et al., 2012); however, prescribing the land surface temperatures is not routinely done in AMIP experiments.

Previous studies that use GCMs with prescribed SSTs have shown the important role land surface temperatures play in driving the global circulation. For example, Chadwick et al. (2013b) use results from an AMIP4 $\mathrm{xCO}_{2}$ experiment and a GCM simulation with an increased solar constant to show that the surface warming patterns in the AMIP4 $\mathrm{xCO}_{2}$ cause changes in the tropical precipitation. Moreover, the meridional land surface temperature gradients over Eurasia and northern Africa are implicated in driving the Asian summer monsoon (Chou, 2003; Turner and Annamalai, 2012) and the recent recovery of Sahel rainfall (Dong and Sutton, 2015), respectively. Nevertheless, in each of the model experiments that Chadwick et al. (2013b), Chou (2003), and Dong and Sutton (2015) undertake, the land surface temperatures are 
allowed to vary freely in response to each of their specified boundary condition perturbations. It is then difficult to determine whether a remote (i.e. away from the region under consideration) land surface temperature response to a boundary forcing subsequently feeds back on the large-scale circulation in a way that acts to enhance or reduce the feature under consideration. By prescribing land surface temperatures in GCMs, and then perturbing them regionally and/or globally, the impact of such feedbacks can be negated somewhat. Such a GCM is described in this paper.

The aims of this study are to

1. document the method and code changes that are applied to a GCM in order to prescribe the land surface temperatures;

2. show that simulations with prescribed and freely varying land surface temperatures (with the land temperatures in the prescribed run being derived from the freely varying simulation in order to avoid spurious effects) are climatologically comparable;

3. document the results of a series of sensitivity experiments where the land surface temperatures are perturbed;

4. show that the atmospheric responses in those perturbation experiments are physically plausible and agree with the results of other studies in the literature; and

5. overall, provide a "proof of concept" by attaining the aims above and show that GCM simulations with prescribed land surface temperature are realistic and have many potential applications.

It should be noted that the experiments in this paper are designed to be sensitivity tests to identify whether the model atmosphere responds in a physically realistic way to the imposed land surface temperature field. The experiments are not designed to answer specific questions about the processes at work but to highlight the types of experiment that can be run with such a model setup.

The model and methods used in this study are given in Sect. 2, which includes descriptions of the source code changes, the development of the land temperature data set, and the experiments undertaken. An overview of the salient results for the global and regional surface air temperature, precipitation (including the diurnal cycle), and mean sea level pressure for each experiment is given in Sect. 3. A detailed discussion and physical interpretation of the results shown in Sect. 3 are given in Sect. 4. Finally, the conclusions and future work/applications are given in Sect. 5.

\section{Model and methods}

\subsection{Model background}

The GCM is the atmosphere-only version of the Australian Community Climate and Earth System Simulator (primarily ACCESS1.0), which is described in more detail in $\mathrm{Bi}$ et al. (2013) and Frauen et al. (2014). ACCESS is configured similarly to the United Kingdom Met Office Unified Model (Met ${ }_{U M}$ ), Hadley Centre Global Environmental Model version 2 (HadGEM2: Martin et al., 2011), and has a horizontal grid spacing of $3.75^{\circ}$ longitude by $2.5^{\circ}$ latitude and 38 vertical levels in this study. Physical processes represented in the model include clouds, precipitation, surface energy exchange, boundary layer processes, and radiation.

Relevant to the experiments used in this study is the surface process parameterization, which is the Met Office Surface Exchange Scheme (MOSES: Cox et al., 1999; Essery et al., 2001). Heterogeneity of the land surface is represented in MOSES by splitting the land into smaller tiles (i.e. subgrid box scale). The tiles can be any combination (fractional) of nine different surface types, which are separated into five vegetated (broadleaf trees, needleleaf trees, two types of grasses, and shrubs) and four non-vegetated (lakes, urban, bare soil, and permanent ice) surfaces. The surface temperature, radiative, sensible, and latent heat fluxes are calculated for each surface type individually and area-weighted gridbox values are calculated from those and passed back into the model. There are also four vertical layers in the soil (at $0.1,0.25,0.65$, and $2.00 \mathrm{~m}$ depth) and snow cover is represented by a single layer (snow cover is not prescribed). More details of the MOSES scheme used in ACCESS can be found in Kowalczyk et al. (2013, 2016). In all simulations listed in Sect. 2.3, both the soil moisture content and deep soil temperatures (i.e. on all four levels described above) are prescribed from climatological values (and updated monthly) in order to minimize feedbacks that may arise from circulation and precipitation changes in these simulations. This soil moisture constraint is applied only for these "proof of concept" experiments (outlined below) and can be removed (i.e. freely varying soil moisture and temperature).

\subsection{Calculating land surface temperatures}

\subsubsection{Original calculation in ACCESS}

This section gives an overview of the processes that are considered for calculating the surface temperature $\left(T_{*}\right)$ in ACCESS in order to show where the model code has been changed (including the names of the subroutines). The calculations for surface temperature are given in more detail by Essery et al. (2001); however, this section only describes the equations that are changed (see Sect. 2.2.3) to prescribe $T_{*}$.

A schematic of the model process for updating $T_{*}$, the surface long-wave $\left(\mathrm{LW}, \mathrm{W} \mathrm{m}^{-2}\right.$ ) and short-wave $\left(\mathrm{SW}, \mathrm{W} \mathrm{m}^{-2}\right.$ ) 


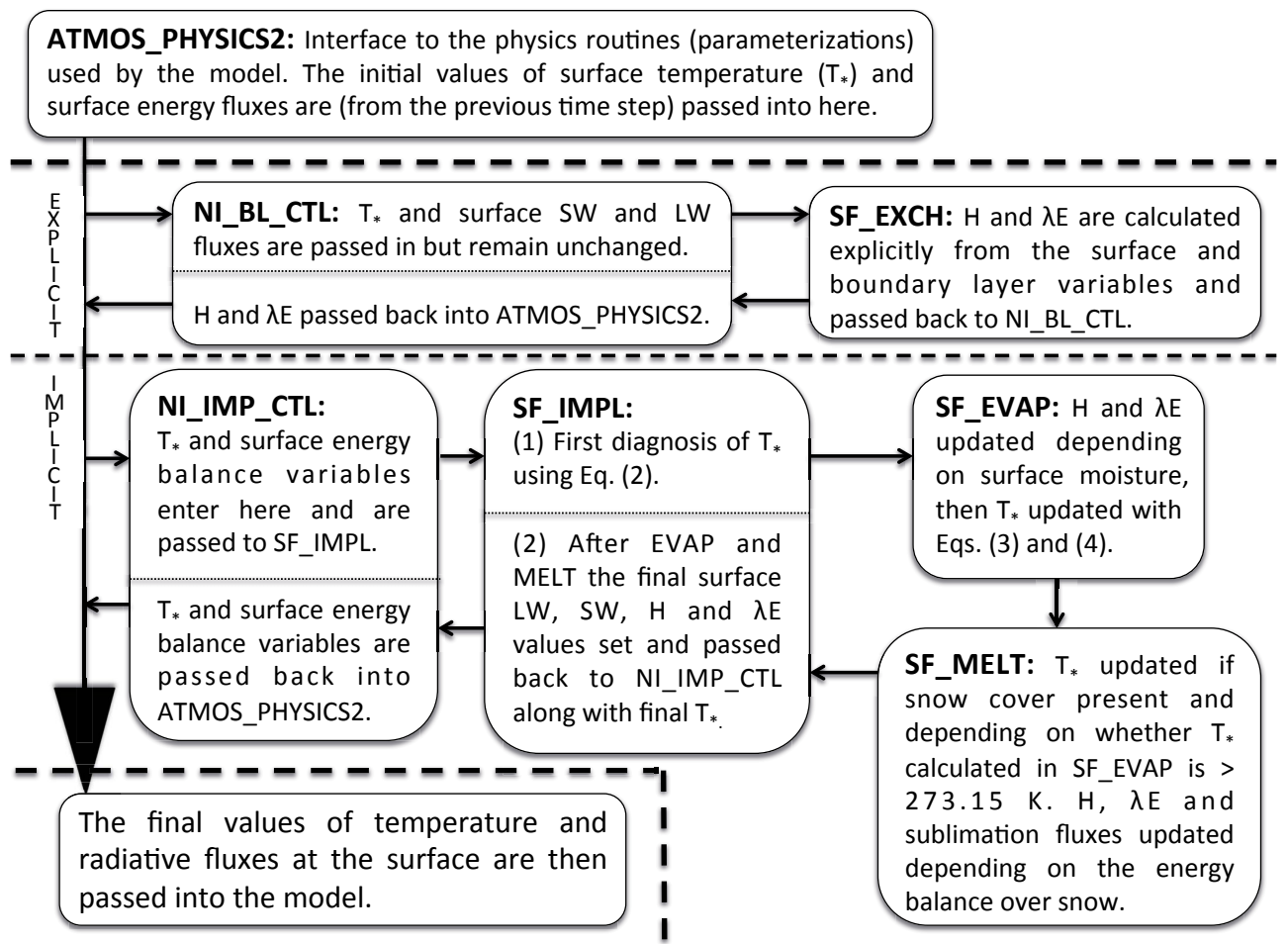

Figure 1. Schematic diagram of the processes involved with calculating the surface temperature and fluxes in ACCESS. Upper-case lettering refers to the names of individual subroutines within the model. The variables are passed from ATMOS_PHYSICS2 through the explicit calculations, then the implicit calculations, and finally back to ATMOS_PHYSICS2 for use elsewhere. Arrows indicate the transfer of variables through subroutines. Solid lines separate the transfer of variables into and out of the same subroutine where applicable.

radiative fluxes, and the surface sensible $\left(H, \mathrm{~W} \mathrm{~m}^{-2}\right)$ and latent $\left(\lambda E, \mathrm{~W} \mathrm{~m}^{-2}\right)$ heat fluxes is shown in Fig. 1. Initially the values of $\mathrm{SW}, \mathrm{LW}, H$, and $\lambda E$ are calculated explicitly at the start of a time step (in SF_EXCH; see Fig. 1) using surface, soil, and boundary layer temperatures from the previous time step (see Essery et al., 2001, for more details). The fluxes are then updated implicitly, at which point the initial estimate of the new value of the surface temperature is calculated from

$T_{*}=T_{\mathrm{s}}+\frac{1}{A_{*}}\left[R_{\mathrm{s}}-H-\lambda E+\frac{C_{\mathrm{c}}}{\Delta t}\left(T_{*}^{\mathrm{prev}}-T_{\mathrm{s}}\right)\right]$,

where $T_{\mathrm{S}}$ is the temperature of the first soil layer beneath the surface at the end of the previous time step $(\mathrm{K}), R_{\mathrm{S}}$ is the net radiation (SW and LW) into the soil layer through the surface $\left(\mathrm{W} \mathrm{m}^{-2}\right), A_{*}$ is the coefficient to calculate the surface heat flux $\left(\mathrm{W} \mathrm{m}^{-2} \mathrm{~K}^{-1}\right), C_{\mathrm{c}}$ is the areal heat capacity of the surface $\left(\mathrm{J} \mathrm{m}^{-2} \mathrm{~K}^{-1}\right), \Delta \mathrm{t}$ is the time step length (s), and $T_{*}^{\text {prev }}$ is the surface temperature from the previous time step $(\mathrm{K})$; all other variables have the same definition as described above. The term $C_{\mathrm{c}} / \Delta \mathrm{t}\left(T_{*}^{\text {prev }}-T_{\mathrm{S}}\right)$ represents the conductive energy flux from the first soil layer to the surface of the soil during the previous time step and is equivalent to the ground heat flux $(G)$. More details on the derivation of Eq. (1) can be found in Best et al. (2005) and Essery et al. (2001, 2003).
Adjustments to the surface sensible and latent heat fluxes are then calculated implicitly in SF_EVAP depending on the availability of surface moisture (Essery et al., 2001). The value of $T_{*}$ calculated in Eq. (1) then needs to be adjusted by an amount that is consistent with (and proportional to) the updated values of the sensible and latent heat fluxes via

$$
\begin{aligned}
& \Delta T_{* \mathrm{EVAP}}=-\frac{\Delta H+\Delta(\lambda E)}{A_{*}}, \\
& T_{* \mathrm{EVAP}}=T_{*}+\Delta T_{* \mathrm{EVAP}},
\end{aligned}
$$

where $\Delta T_{*_{\mathrm{EVAP}}}(\mathrm{K})$ is the land surface temperature increment resulting from the adjustments to the sensible $(\Delta H)$ and latent heat $(\Delta \lambda E)$ fluxes $\left(\mathrm{W} \mathrm{m}^{-2}\right)$ and $\mathrm{T}_{*_{\mathrm{EVAP}}}(\mathrm{K})$ is the adjusted value of land surface temperature following evaporation ( $T_{*}$ and $A_{*}$ have the same definition as those in Eq. 1). If there is no snow present within the grid box, then $T_{*_{\mathrm{EVAP}}}$ is that final value of land surface temperature $\left(T_{*_{\text {final }}}, \mathrm{K}\right)$ and is passed back into ATMOS_PHYSICS2. If there is lying snow however, then $T_{*_{\text {EVAP }}}$ is passed into the SF_MELT routine (Fig. 1) to account for any melting ice and snow on land tiles. The surface energy fluxes over snow and ice (sublimation and sensible heating) are also adjusted in SF_MELT. If the value of $T_{\text {*EVAP }}$ from Eq. (4) is above freezing for water $\left(T_{m}, 273.15 \mathrm{~K}\right)$, then the temperature is adjusted by a value $\Delta T_{*_{\mathrm{MLT}}}(\mathrm{K})$, which is either 
1. back to freezing if there is sufficient snow that it cannot be melted within a time step ( $30 \mathrm{~min}$ in this case) or

2. by an amount proportional to the energy required to remove all the snow on the tile if it can all be removed within a time step.

The final value of surface temperature that the atmosphere uses in the rest of the time step $\left(T_{*_{\text {final }}}, \mathrm{K}\right)$ is therefore given as

$T_{*_{\text {final }}}=T_{*_{\mathrm{EVAP}}}+\Delta T_{*_{\mathrm{MLT}}}$.

If there is no melting, then $\Delta T_{*_{\mathrm{MLT}}}$ is zero, but if melting does occur, then the surface fluxes are updated by an amount proportional to the value of $\Delta T_{*_{\mathrm{MLT}}}$. Therefore, the value of $T_{*}$ may differ within the model time step between the first guess (Eq. 1) and the final value (Eq. 4), which also applies to the surface fluxes ( $H, \mathrm{LE}$, and sublimation flux).

\subsubsection{Creating the input surface temperature field}

Given that ACCESS uses a 30 min time step, in order to prescribe the land surface temperatures, a data set that is available for all surface tiles and at $30 \mathrm{~min}$ intervals is required. Such a data set does not exist in the observational record and so, therefore, in order to represent both the diurnal and seasonal cycles, the optimal solution is to take the surface temperatures from a simulation where they are allowed to vary freely. In this study, surface temperatures are taken from each time step and tile from a 50-year long simulation that uses prescribed climatological SSTs and sea ice fractions (denoted as FREE in Table 1). Data are stored from each time step and surface tile type so that the prescribed temperature field can account for

1. the diurnal and seasonal cycles in surface temperature and

2. the surface heterogeneity over land (i.e. temperatures on individual tiles).

Starting at 00:00 UTC on 1 January, all 50 values for that specific time produced by the FREE simulation (i.e. one for each year) are averaged together to produce a representative mean temperature on each land tile and saved. The process is then repeated on all land tiles for 00:30 UTC on 1 January. The process is repeated for all time steps over the year to produce a climatological land temperature field that contains a mean diurnal cycle for each day of the year on each land surface tile. This is illustrated in Fig. 2 for a selection of different grid points in the model (values are the grid-box means across all surface tiles). These grid points are located within a tropical (Amazonia), sub-tropical (central Australia), highlatitude (northern Asia), and mid-latitude (Europe) region. The grey lines show the 30 min surface temperatures at those points for all 50 years of FREE on 1-2 January and the black solid line is the average over those 50 years for each $30 \mathrm{~min}$ time step (Fig. 2, middle column). The variability in surface temperatures is reduced by taking the average; however, diurnal variability in the surface temperature field can be seen at each of those grid points, which is larger in the tropics than at mid-latitudes. There are also some discontinuities in the original time step data, which are likely to be associated with the radiative calculations within ACCESS (occurring every $3 \mathrm{~h}$ ).

In Fig. 2 (third column), the mean diurnal cycle for each day (black) and the daily mean surface temperature (yellow) are plotted. There is a clear seasonal and diurnal cycle, which is representative of the FREE simulation at each of those selected grid points.

Initial test experiments with the time step data resulted in two problems.

1. The time step $(30 \mathrm{~min})$ data set is too large to be read into the current ACCESS framework as one single input field.

2. Surface air temperatures ( $1.5 \mathrm{~m}$ above the surface) over the Antarctic were lower by $>2 \mathrm{~K}$ relative to FREE.

To combat the first problem, surface temperatures are read into the model every $3 \mathrm{~h}$ and interpolated hourly between those points (orange line overlaid in Fig. 2, middle column). The results of the $30 \mathrm{~min}$ and 3-hourly temperature simulations have almost indistinguishable mean climate states (not shown). Therefore, the 3-hourly data are used in the simulations outlined below.

In order to prevent the negative temperature anomalies from developing over Antarctica in the prescribed runs relative to the FREE simulation, the surface temperatures on permanent land ice tiles were allowed to vary freely. The impact of this exception is small and discussed in Sect. 4.

\subsubsection{Implementing the climatological land temperature data set}

In order to prescribe the land surface and sea ice temperature, Eq. (1) in SF_IMPL (Fig. 1) is simply changed to

$T_{*}=T_{\mathrm{PRES}}$,

where $T_{\text {PRES }}$ is the input land surface temperature $(\mathrm{K})$ field. Furthermore, the increments to the surface $H$, LE, sublimation, and snowmelt are still calculated in SF_EVAP and SF_MELT (Fig. 2), but the surface temperature increments (Eqs. 3 and 4) are removed so that the surface temperature cannot change. The variables in the surface radiation budget are then set to their final values, which depend upon $T_{\text {PRES }}$ only.

\subsection{Experiments}

The full list of experiments considered in this study is outlined in Table 1 along with the abbreviations used in the rest 
(a) Amazonian point

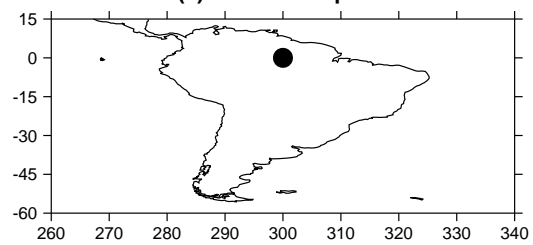

(d) Australian poin

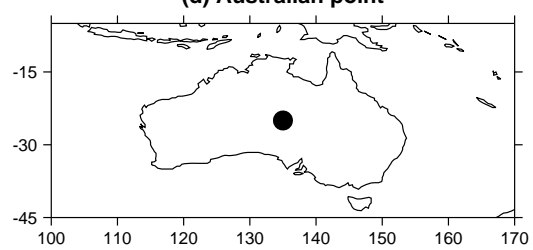

(g) Northen Asia point

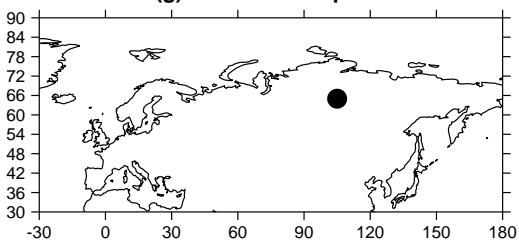

(j) European point

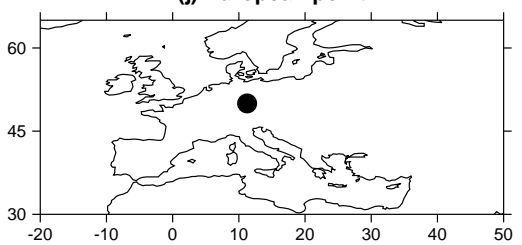

(b) Amazonia $1^{\text {st }}-2^{\text {nd }}$ January

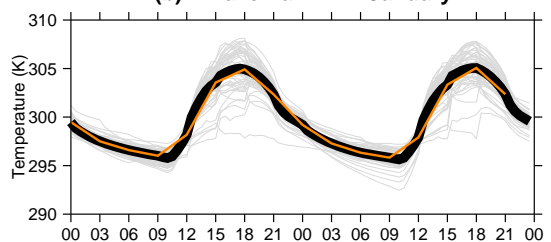

(e) Australia $1^{\text {st }}-2^{\text {nd }}$ January

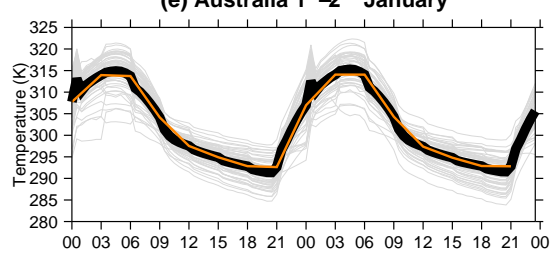

(h) N. Asia $1^{\text {st }}-2^{\text {nd }}$ January

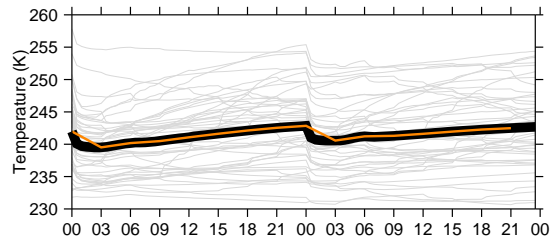

(k) Europe $1^{\text {st }}-2^{\text {nd }}$ January

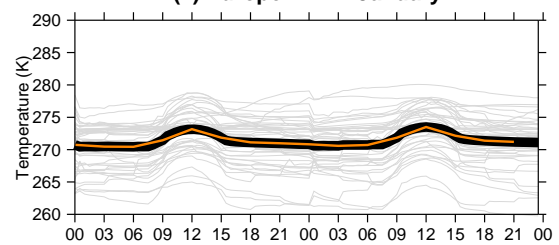

(c) Amazonia $300^{\circ} \mathrm{E}$ and $0^{\circ}$

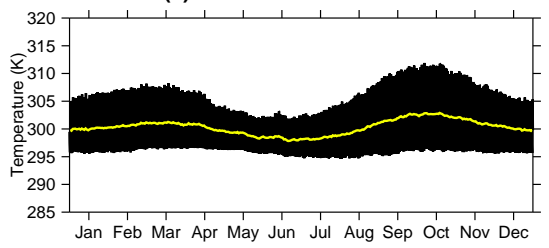

(f) Australia $135^{\circ} \mathrm{E}$ and $-25^{\circ}$

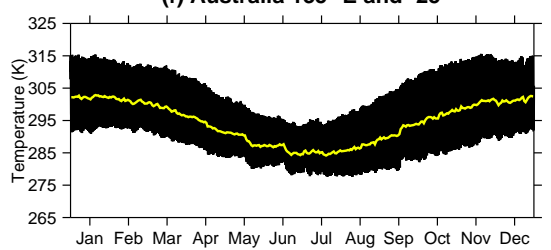

(i) N. Asia $105^{\circ} \mathrm{E}$ and $65^{\circ}$

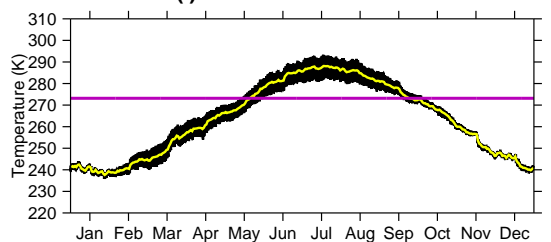

(I) Europe $11.25^{\circ} \mathrm{E}$ and $50^{\circ}$

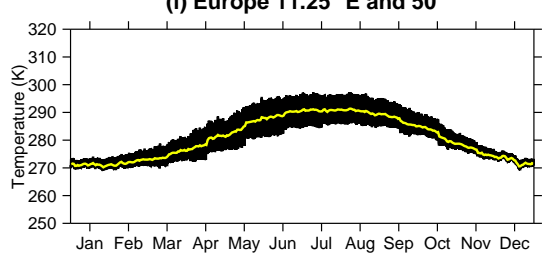

Figure 2. Examples of how the surface temperature $(\mathrm{K})$ inputs were produced at individual grid points. Left column: the locations of the example grid points. Middle column: corresponding surface temperature values for those points in the left column on 1 and 2 January. Grey lines are the surface temperatures for each of the 50 years, the black lines represent the time-step mean ( 30 min) values from those 50 years on 1 and 2 January, and the orange lines represent the 3-hourly input-hourly interpolated temperature field described in Sect. 2.2.2. Right column: the time-step mean values (black line) and the daily mean surface temperature (yellow line, which highlights the seasonal cycle) The magenta line in (i) indicates $273.15 \mathrm{~K}$ (i.e. the freezing temperature of liquid water).

of this paper. A more detailed description of each experiment is given below.

The following experiments are designed to either create the data necessary to prescribe the land surface temperatures or use those data. These first three experiments represent a suite of control simulations.

1. FREE. This simulation uses prescribed, climatological soil moisture, deep soil temperatures, SSTs, and sea ice fractions (monthly mean, 1961-1990 values), but allows the land temperatures to vary freely. The surface temperatures from each surface type are used in each of the subsequent experiments below. This is denoted as the "free running" (FREE) simulation.

2. CON1. Control run number 1 , which is the same as FREE, except the surface land temperatures are prescribed using the data set described in Sect. 2.2.2.
3. CON2. Control run number 2 , which is identical to CON1, except different initial conditions are used for the atmosphere.

Perturbation experiments are described in the following list where the surface state is changed by either increasing $(+10 \mathrm{~K})$ or reducing $(-10 \mathrm{~K})$ the surface land temperatures over specific areas. The value of $10 \mathrm{~K}$ is intentionally chosen in order to induce a large and visible response in the atmosphere and not because such perturbations are based on actual observations (i.e. these are purely sensitivity experiments). If the resulting circulation responses are consistent with known physical processes, then this is indicative that the surface temperatures are being specified in the correct way. These perturbation experiments are the following.

4. ALL10K. Identical to CON1 except all land surface temperatures are increased by $10 \mathrm{~K}$. This simulation is used to illustrate how the global circulation responds to 
Table 1. A list of the experiments run with ACCESS. The SST and sea ice fractional cover are climatological mean values representative of 1961-1990.

\begin{tabular}{|c|c|c|c|c|}
\hline $\begin{array}{l}\text { Simulation } \\
\text { (abbreviation) }\end{array}$ & $\begin{array}{l}\text { Run length } \\
\text { (years) }\end{array}$ & $\begin{array}{l}\text { Land surface } \\
\text { temperatures }\end{array}$ & $\begin{array}{l}\text { Ice cover and } \\
\text { SST }\end{array}$ & $\begin{array}{l}\text { Perturbation } \\
\text { to land temperature }\end{array}$ \\
\hline $\begin{array}{l}\text { Free-running } \\
\text { (FREE) }\end{array}$ & 50 & Freely evolving & $\begin{array}{l}\text { Prescribed 12-month } \\
\text { periodic climatology }\end{array}$ & None \\
\hline $\begin{array}{l}\text { Control run } 1 \\
(\mathrm{CON} 1)\end{array}$ & 50 & $\begin{array}{l}\text { Prescribed } 3 \mathrm{~h} \\
\text { interpolating climatology }\end{array}$ & As in FREE & None \\
\hline $\begin{array}{l}\text { Control run } 2 \\
(\mathrm{CON} 2)\end{array}$ & 50 & As in CON1 & As in FREE & None \\
\hline $\begin{array}{l}\text { Heat all land } \\
(\text { ALL10K) }\end{array}$ & 50 & As in $\mathrm{CON} 1$ & As in FREE & $\begin{array}{l}+10 \mathrm{~K} \text { over all } \\
\text { land points }\end{array}$ \\
\hline $\begin{array}{l}\text { Heat Amazonia } \\
\text { (AMA10K) }\end{array}$ & 50 & As in $\mathrm{CON} 1$ & As in FREE & $\begin{array}{l}+10 \mathrm{~K} \text { over all } \\
\text { Amazonian land points }\end{array}$ \\
\hline $\begin{array}{l}\text { Heat Maritime } \\
\text { Continent }(\mathrm{MC} 10 \mathrm{~K})\end{array}$ & 50 & As in $\mathrm{CON} 1$ & As in FREE & $\begin{array}{l}+10 \mathrm{~K} \text { over all Maritime } \\
\text { Continent land points }\end{array}$ \\
\hline $\begin{array}{l}\text { Heat Australia } \\
\text { (AUS10K) }\end{array}$ & 50 & As in CON1 & As in FREE & $\begin{array}{l}+10 \mathrm{~K} \text { over all } \\
\text { Australian land points }\end{array}$ \\
\hline $\begin{array}{l}\text { Heat North } \\
\text { America (AM10K) }\end{array}$ & 50 & As in CON1 & As in FREE & $\begin{array}{l}+10 \mathrm{~K} \text { over all North } \\
\text { American land points }\end{array}$ \\
\hline $\begin{array}{l}\text { Cool North } \\
\text { America (AMm10K) }\end{array}$ & 50 & As in CON1 & As in FREE & $\begin{array}{l}-10 \mathrm{~K} \text { over all North } \\
\text { American land points }\end{array}$ \\
\hline
\end{tabular}

an artificial enhancement of the land-sea thermal contrast.

5. AMA10K. The same as CON1 except the land temperatures within the box $285-310^{\circ} \mathrm{E}$ and $5^{\circ} \mathrm{N}-17.5^{\circ} \mathrm{S}$ are increased by $10 \mathrm{~K}$. This simulation is run to identify the seasonal and hemispheric impacts of heating Amazonia.

6. MC10K. The same as CON1 except the land temperatures within the box $100-160^{\circ} \mathrm{E}$ and $10^{\circ} \mathrm{N}-10^{\circ} \mathrm{S}$ are increased by $10 \mathrm{~K}$. This simulation is run to identify the seasonal and hemispheric impacts of heating the land within the western Pacific warm pool.

7. AUS10K. Identical to CON1 except surface temperatures are increased by $10 \mathrm{~K}$ over Australia. This is to identify the impact of land surface heating on the Australian monsoon and the Southern Hemisphere (SH) extratropical circulation.

8. AM10K. Identical to CON1 except surface temperatures over the North American continent are increased by $10 \mathrm{~K}$. This simulation is run to identify the impact of heating a large Northern Hemisphere $(\mathrm{NH})$ continent on the extratropical circulation.

9. AMm10K. Identical to CON1 except surface temperatures over the North American continent are decreased by $10 \mathrm{~K}$. This simulation is run to identify the impact of cooling a large NH continent on the extratropical circulation.

\section{Results}

\subsection{Surface air temperature at $1.5 \mathrm{~m}\left(T_{1.5}\right)$}

The differences in $T_{1.5}$ between CON1 and FREE are plotted in Fig. 3a. The CON1 simulation has lower $T_{1.5}$ over the Arctic $(-0.1$ to $-0.5 \mathrm{~K})$ between $60^{\circ} \mathrm{E}$ and $60^{\circ} \mathrm{W}$ and higher $T_{1.5}(0.1$ to $0.25 \mathrm{~K})$ over parts of Africa. Elsewhere, $T_{1.5}$ differences between CON1 and FREE are typically within $\pm 0.1 \mathrm{~K}$ (i.e. small) and not statistically significant. There are also slight differences between $T_{1.5}$ values in CON2 relative to CON1 (for example over both poles, Fig. 3b); however, those differences are not statistically significant and indicate that $\mathrm{CON} 2$ and $\mathrm{CON} 1$ are climatologically indistinguishable.

Increasing the prescribed surface temperatures on all land points (ALL10K) acts to significantly increase $T_{1.5}$ by more than $2.0 \mathrm{~K}$ (and by more than $8.0 \mathrm{~K}$ over northern Asia) over all land surfaces (Fig. 3c) relative to CON1. There are also increases in $T_{1.5}(>2.0 \mathrm{~K})$ over the Arctic adjacent to the continents. Furthermore, $T_{1.5}$ values are significantly higher over the western Pacific, north-western Atlantic, western Indian Ocean, and parts of the Southern Ocean. Nevertheless, the largest changes in $T_{1.5}$ are primarily over the land surface, with only small temperature changes (typically within $\pm 0.5 \mathrm{~K}$ ) over the ocean where SSTs are unchanged (i.e. the same as in CON1).

In both the AMA10K and MC10K experiments, the largest increases in $T_{1.5}$ (relative to CON1) are restricted to Amazonia and the islands of the Maritime Continent (Fig. 3d and e, respectively); however, there is evidence of the atmosphere responding remotely from the surface temperature increases. 
For example, there are alternating positive and negative $T_{1.5}$ anomalies to both the north-east and south-east of the Amazon (Fig. 3d). In MC10K, similar (but weaker) alternating positive and negative $T_{1.5}$ anomalies extend to the north-east and south-east of the Maritime Continent too (Fig. 3e).

In the AUS10K simulation, $T_{1.5}$ is higher over the Australian continent relative to CON1 (Fig. 3f). Despite the strong increase in $T_{1.5}$ over Australia, the only significant remote responses are weak increases in $T_{1.5}(0.1$ to $0.25 \mathrm{~K})$ over the Southern Ocean between 0 and $60^{\circ} \mathrm{W}$ and weak decreases $(-0.1$ to $-0.5 \mathrm{~K})$ over Antarctica.

The increases in $T_{1.5}$ for AM10K are largest over North America (Fig. 3g), and there is also evidence of increased temperatures $(0.1-1.0 \mathrm{~K})$ to the east of the continent (similar to ALL10K - compare Fig. 3c and g). There are also higher values of $T_{1.5}$ over the Arctic, central Asia and the Sahara that are statistically significant, which again indicates that there is a remote response to increasing the surface temperatures over North America. In the AMm10K experiment almost the opposite is true. $T_{1.5}$ values are lower over North America, the Arctic, and the western Atlantic Ocean (Fig. 3h). Moreover, there are reductions in $T_{1.5}$ over central Asia (approximately -0.1 to $-0.5 \mathrm{~K}$ ), albeit weaker than the increase in $T_{1.5}$ induced in AM10K (compare Fig. 3g and h).

Interestingly, in the experiments with higher land surface temperatures (ALL10K, AMA10K, MC10K, AUS10K, and $\mathrm{AM} 10 \mathrm{~K})$, the $T_{1.5}$ responses are similar to those of the CMIP5 multi-model ensemble average for the end of the 21st century (2081-2100) under RCP8.5 (i.e. high greenhouse gas concentrations; see Fig. 12.11 in Collins et al., 2013). Similarly, the negative $T_{1.5}$ anomalies over North America in AMm10K are of a similar magnitude to those simulated over land for the Last Glacial Maximum (see Fig. 2 in Harrison et al., 2014).

\subsection{Precipitation}

\subsubsection{Regional annual mean precipitation}

The differences in the annual mean precipitation between CON1 and FREE are generally within $\pm 8 \%$ (Fig. 4a). The largest percentage differences primarily occur over the Arctic circle (reductions $>4 \%$ ) and the Amazon (increases $>4 \%)$. Nevertheless, the differences in precipitation outside these two regions (Arctic and Amazon) are largely statistically insignificant. Furthermore, for CON2 relative to CON1 (Fig. 4b), there are only small and non-significant differences in precipitation (within $\pm 8 \%$ ), which suggests that there is little impact on precipitation from changing the initial conditions.

For ALL10K relative to CON1 there are statistically significant changes to the precipitation over all land areas (Fig. 4c); however (unlike with $T_{1.5}$ ), the differences are not all the same sign. Precipitation increases by more than $30 \%$ over northern South America, Africa, South-east Asia, the islands of the Maritime Continent, and northern and eastern Australia, but decreases by more than $30 \%$ over central North America, central Asia, and India. There are also large reductions (greater than $30 \%$ ) in precipitation over the central Atlantic Ocean, Indian Ocean and much of the Pacific Ocean, while there is an approximate $10 \%$ increase in precipitation over the Southern Ocean.

In both of the tropical experiments (AMA10K and $\mathrm{MC} 10 \mathrm{~K})$, precipitation increases by $>50 \%$ where the surface temperatures are increased (compare Fig. $4 \mathrm{~d}$ and e with Fig. 3d and e, respectively). There are also precipitation anomalies of alternating sign that extend from the Amazon and the Maritime Continent to the north-east and south-east that are statistically significant (similar to the $T_{1.5}$ differences - Fig. 3d and e), which suggests the increased tropical land surface temperatures are affecting precipitation remotely (Fig. 4d and e). Moreover, the response of tropical precipitation in AMA10K over Africa, India, the tropical Atlantic, and Pacific is much stronger than in MC10K (the largest differences are confined to the western Pacific in MC10K).

Increasing Australian land surface temperatures causes precipitation to increase in the north and east of the continent but to decrease over the eastern Indian Ocean (Fig. 4f). There is very little significant change in the precipitation field away from the Australian continent and eastern Indian Ocean.

For AM10K, increased precipitation coincides with the surface heating except in the centre of the continent (this also occurs in ALL10K - compare Fig. 4g and c). There is also higher precipitation over the Arctic and Greenland. Conversely, there is lower precipitation in the Gulf of Mexico and the eastern Pacific. For AMm10K, there is a reduction in precipitation throughout North America, which extends over Greenland and into the Arctic (Fig. 4h). There are also significant increases in precipitation over the North Atlantic and the North Pacific, with decreased precipitation over northern Africa.

\subsubsection{Diurnal cycle in the tropics}

When prescribing the surface temperatures it is important to maintain the diurnal cycle, particularly in regards to the impact of the daily heating and cooling of the land surface on tropical convection. Accepting that ACCESS (Ackerley et al., 2014, 2015) and other GCMs (Yang and Slingo, 2001; Dai and Trenberth, 2004; Dai, 2006; Dirnmeyer et al., 2012) produce convective rainfall too early in the day relative to observations, the same process should also occur in the prescribed simulations outlined in Sect. 2.3. Nevertheless, the model needs to be representative of the free-running simulation, and therefore the early triggering of convective rainfall is expected. In order to assess this, the mean diurnal cycle of convective rainfall is plotted in Fig. 5 for tropical land grid points in 
(a) CON1 - FREE

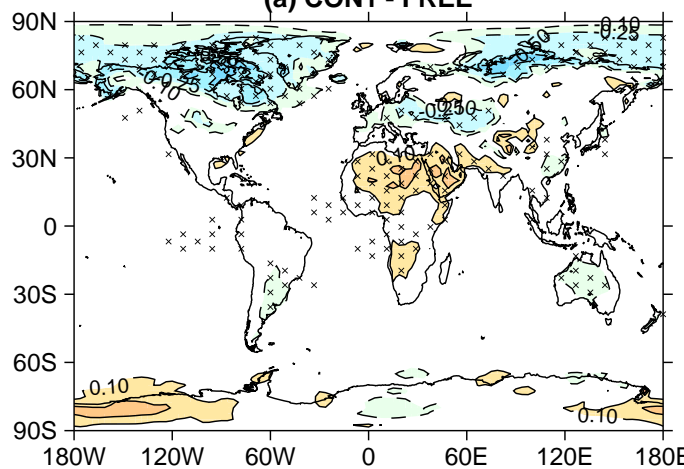

(c) ALL10K - CON1

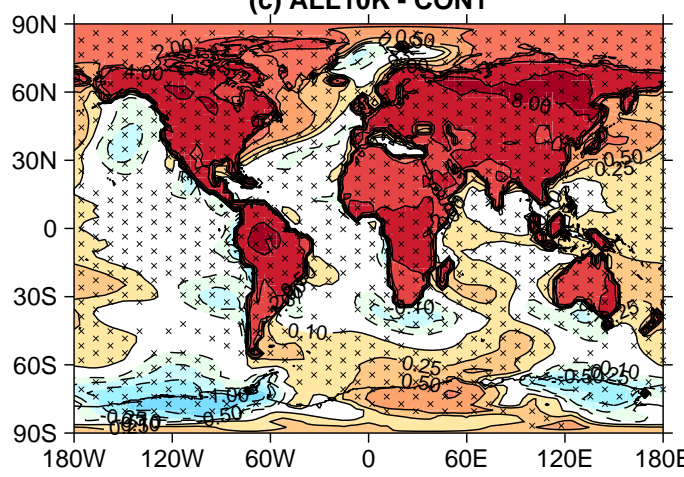

(e) MC10K - CON1

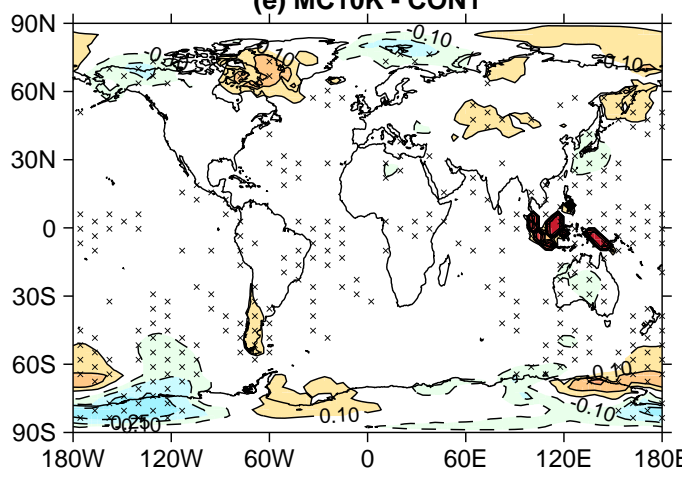

(g) AM10K - CON1
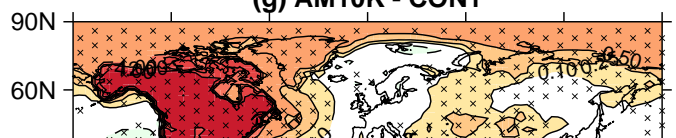

$30 \mathrm{~N}$

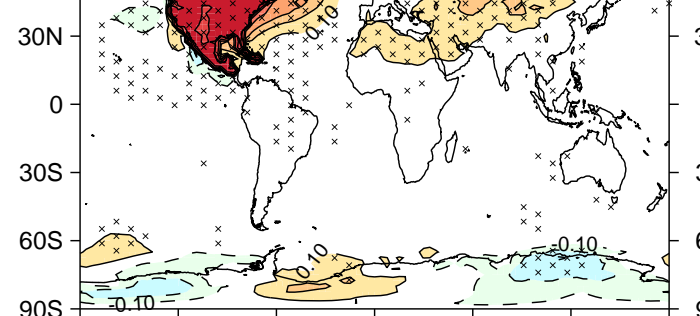

(b) CON2 - CON1

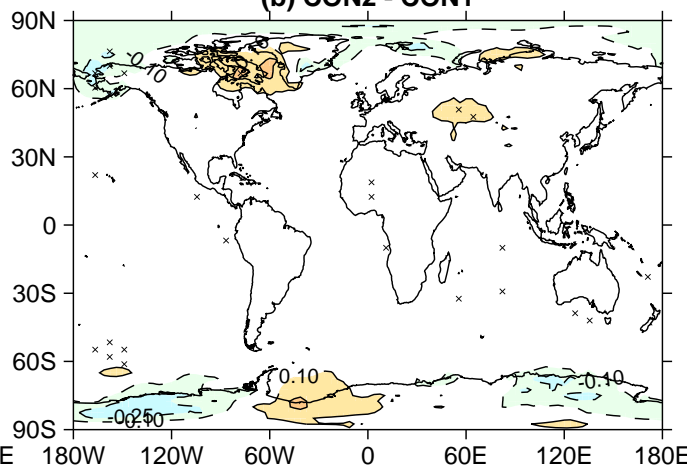

(d) AMA10K - CON1

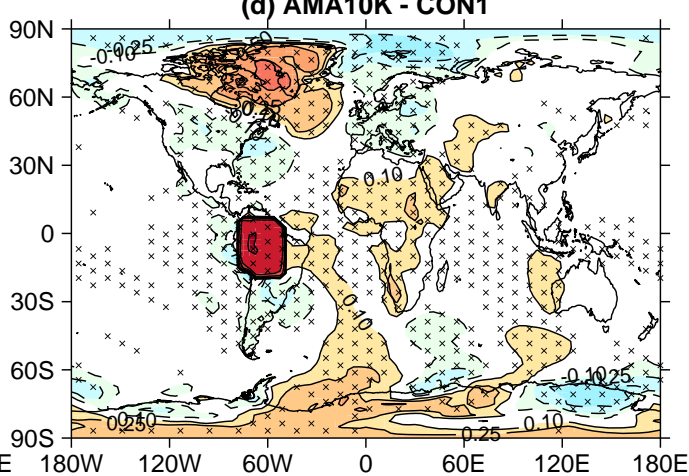

(f) AUS10K - CON1

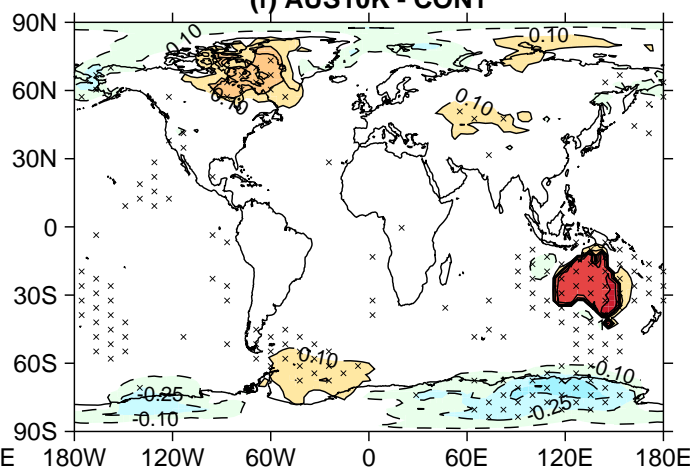

(h) AMm10K - CON1

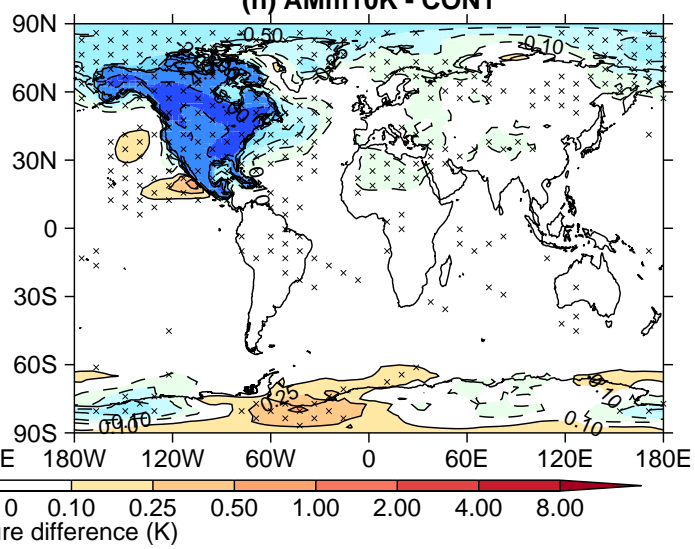

Figure 3. Differences in annual mean surface air temperature at $1.5 \mathrm{~m}$ (K) for (a) CON1 - FREE, (b) CON2 - CON1, (c) ALL10K - CON1, (d) AMA10K - CON1, (e) MC10K - CON1, (f) AUS10K - CON1, (g) AM10K - CON1, and (h) AMm10K - CON1. Values of $p \leq 0.05$ are denoted with an $\mathrm{x}$. 
(a) CON1 - FREE

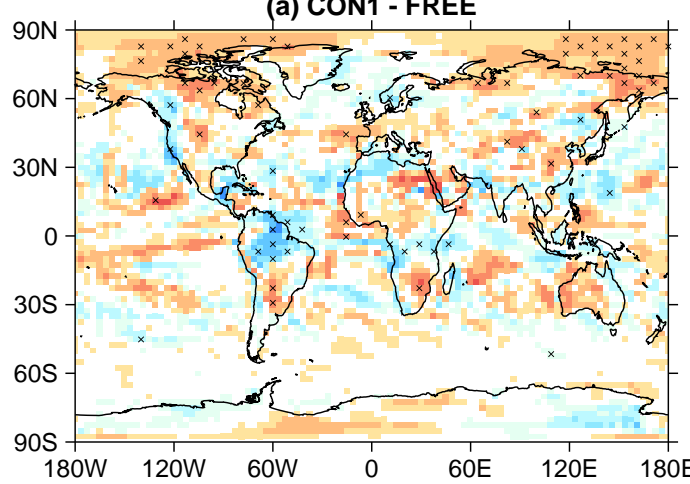

(c) ALL10K - CON1

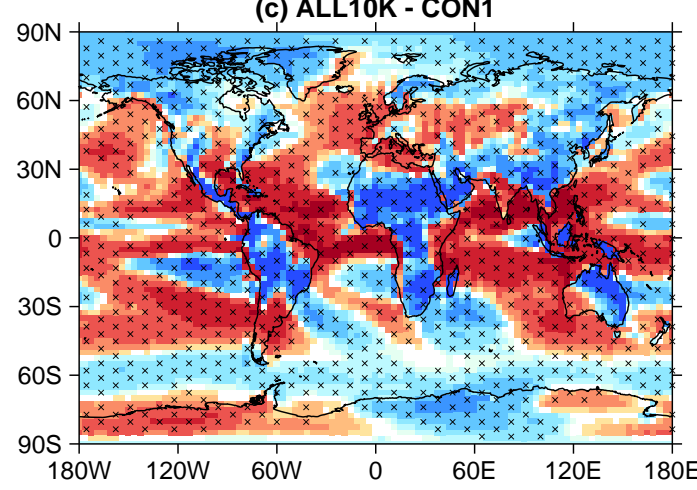

(e) MC10K - CON1

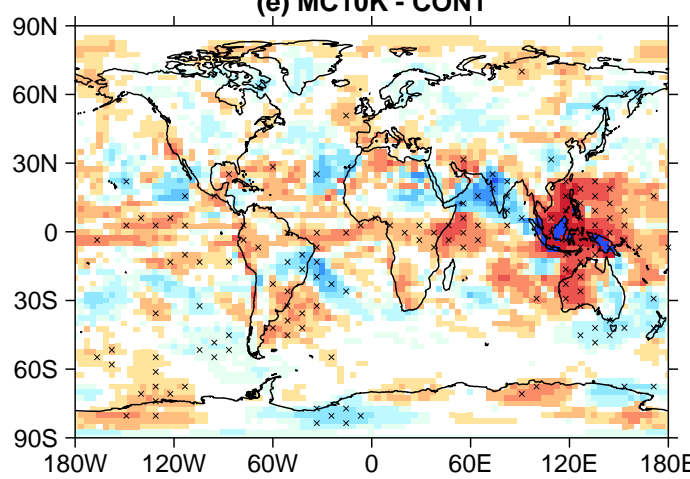

(g) AM10K - CON1

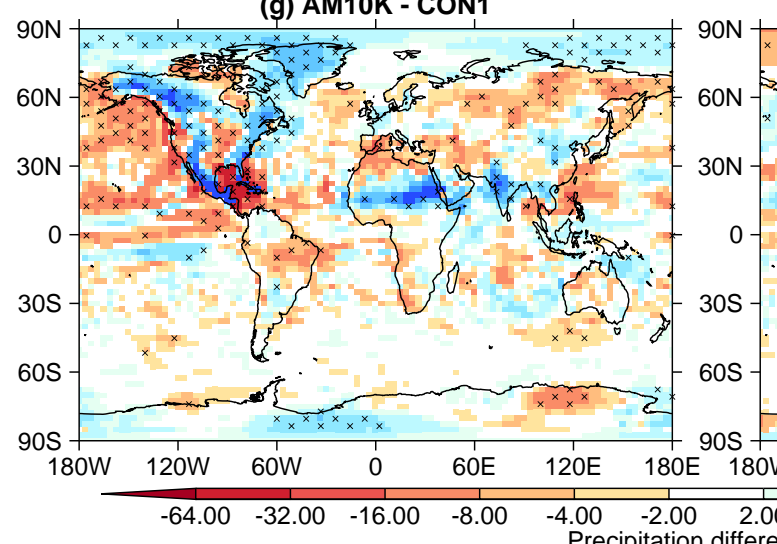

(b) CON2 - CON1

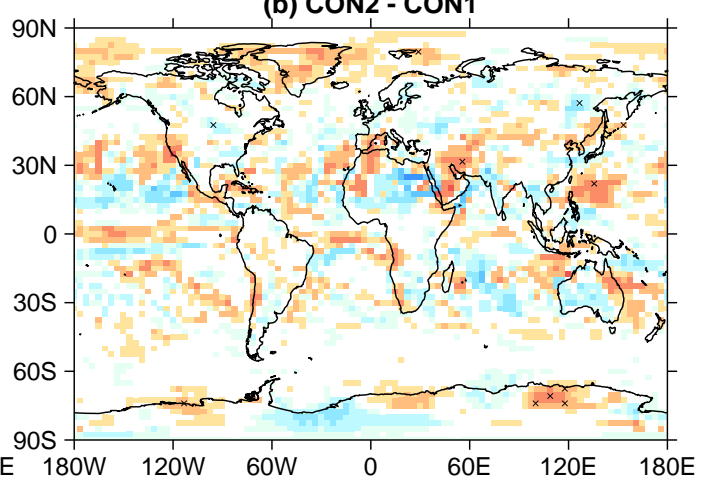

(d) AMA10K - CON1

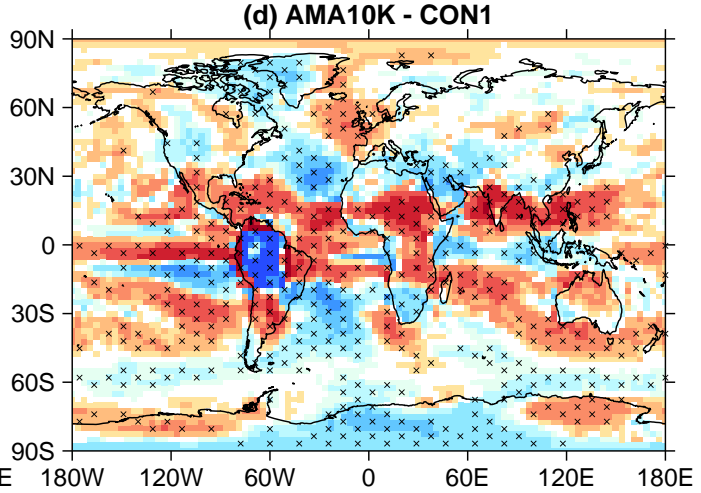

(f) AUS10K - CON1

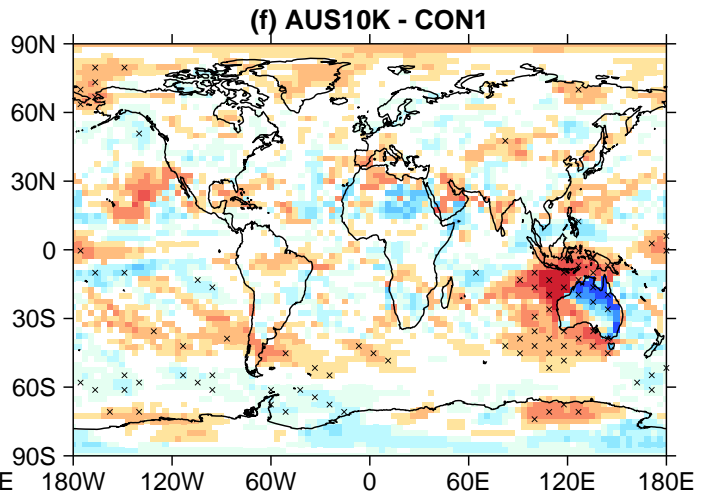

(h) AMm10K - CON1

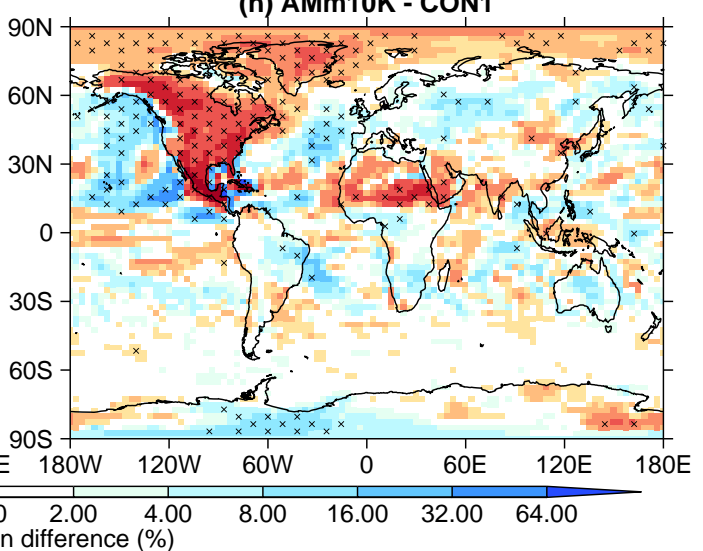

Figure 4. Differences in annual mean precipitation (\%) for (a) CON1 - FREE, (b) CON2 - CON1, (c) ALL10K - CON1, (d) AMA10K CON1, (e) MC10K - CON1, (f) AUS10K - CON1, (g) AM10K - CON1, and (h) AMm10K - CON1. Values of $p \leq 0.05$ are denoted with an $\mathrm{x}$. 
1. West Africa, $0^{\circ} \mathrm{E}, 15^{\circ} \mathrm{N}$ (June-July-August, JJA, mean for a $\mathrm{NH}$ monsoon region), Fig. 5a;

2. northern Australia, $135^{\circ} \mathrm{E}, 15^{\circ} \mathrm{S}$ (December-JanuaryFebruary, DJF, mean for a SH monsoon region), Fig. 5b;

3. the Maritime Continent (Borneo), $112.5^{\circ} \mathrm{E}, 0^{\circ}$ (annual mean for an equatorial island), Fig. $5 \mathrm{c}$; and

4. northern South America (central Amazonia), $300^{\circ} \mathrm{E}, 0^{\circ}$ (annual mean for an equatorial mid-continent point), Fig. 5d.

In West Africa (Fig. 5a), convective rainfall peaks around 10:30 local time (LT) in FREE. Both CON1 and CON2 have peak rainfall around 10:30-13:30 LT, with higher rainfall between 13:30 and 19:30 LT. Despite these differences the diurnal cycle of rainfall is maintained in both CON1 and CON2.

Convective rainfall in northern Australia peaks at 11:00 LT in FREE, CON1, and CON2; however, as over West Africa, the prescribed simulations have higher precipitation in the afternoon (around 17:00 LT). Despite the higher rainfall around 17:00 LT, the diurnal cycle still occurs in the prescribed simulations. Interestingly, the secondary peak in rainfall (around 02:00 LT) associated with the modelled diurnal cycle of the heat low circulation (as discussed by Ackerley et al., 2014, 2015 ) is represented in each of the prescribed simulations. This suggests that the diurnal cycle of the low-level atmospheric circulation at this point is also maintained in CON1 and CON2.

For the Maritime Continent (Fig. 5c), the peak in convective rain occurs at 11:30 LT in all simulations; however, the rainfall amounts are slightly higher in CON1 and CON2. Moreover, the afternoon rainfall is slightly higher in CON1 and CON2 relative to FREE (as with northern Australia and West Africa), but the overall diurnal cycle is maintained (including the secondary peak around 02:30 LT).

Finally, peak convective rainfall occurs at 13:30 LT in all simulations for the Amazonian point (Fig. 5d); however, CON1 and CON2 both have higher accumulated precipitation than the FREE simulation between 07:30 and 19:30 LT, which agrees with the region of increased annual mean precipitation in Fig. 4a. Nevertheless, the diurnal cycle in convective precipitation is again maintained in both $\mathrm{CON} 1$ and CON2 when the temperatures are prescribed as they are in the other tropical regions.

\subsection{Mean sea level pressure}

The differences in mean sea level pressure (MSLP) between FREE and CON1 (Fig. 6a) generally lie within $\pm 0.5 \mathrm{hPa}$ of each other across the globe and are not statistically significant. Similarly, for CON2 relative to CON1 (Fig. 6b) the differences in MSLP are not statistically significant across almost all of the globe.

The largest differences in MSLP occur in the ALL10K experiment, with reductions of 0.5 to $2.0 \mathrm{hPa}$ over most global land surfaces, the Atlantic Ocean, the Arctic, and the Southern Ocean between 180 and $30^{\circ} \mathrm{W}$ (Fig. 6c). There are increases in MSLP of 0.5 to $8 \mathrm{hPa}$ over the North Atlantic, North and South Pacific, and the Southern Ocean between $20^{\circ} \mathrm{W}$ and $180^{\circ} \mathrm{E}$. Increasing the global land surface temperature is therefore having a large impact on the whole global circulation and is not just restricted to over the land.

There are also significant changes in global MSLP in both the AMA10K and MC10K simulations. The MSLP decreases over the Amazon by more than $4 \mathrm{hPa}$ in AMA10K, with reductions of more than $0.5 \mathrm{hPa}$ over much of the Atlantic Ocean (Fig. 6d). Over the Maritime Continent MSLP is only lower by approximately $0.5 \mathrm{hPa}$ (Fig. 6e). Despite the weaker local MSLP response in MC10K relative to AMA10K, both simulations have statistically significant MSLP anomalies (of alternating sign) that extend from the tropics into the mid-latitudes, which suggests that there is also a remote circulation response to the tropical surface temperature perturbations.

In the AUS10K experiment (Fig. 6f), there is a reduction in MSLP over the Australian continent from the surface heating; however, there are also statistically significant increases in MSLP over the Southern Ocean and decreases over the Antarctic. Heating the Australian continent therefore appears to affect both the SH mid-to-high latitude and the local continental-scale circulations.

Similarly, increasing and decreasing North American land surface temperatures has a large impact on the $\mathrm{NH}$ midlatitude circulation. An increase in North American land surface temperature decreases the MSLP locally by $0.5-2.0 \mathrm{hPa}$, but there is also lower MSLP over western Europe (Fig. 6g). Conversely, the MSLP is $0.5-2.0 \mathrm{hPa}$ higher over eastern Asia and the North Pacific. When the North American continental surface temperatures are decreased (AMm10K) the MSLP increases locally by $0.5-2.0 \mathrm{hPa}$ (also over Greenland), with lower MSLP (again $0.5-2.0 \mathrm{hPa}$ ) over eastern Asia and the North Pacific (Fig. 6h).

\section{Discussion}

\subsection{Control experiments}

\subsubsection{FREE vs. CON1}

Over most of the globe, the differences in $T_{1.5}$ between FREE and $\mathrm{CON} 1$ are within $\pm 0.1 \mathrm{~K}$ (unshaded in Fig. 3a). Importantly, the differences in $T_{1.5}$ over the Antarctic in CON1 relative to FREE are not statistically significant (Fig. 3a). Therefore, despite allowing the Antarctic surface temperatures to vary freely in CON1, the surface air temperatures over the Antarctic are unaffected as a result of prescribing the surface temperatures over all other land surface tiles. Nevertheless, there are some regions where $T_{1.5}$ is significantly different between FREE and CON1, for example over the NH high 
(a) West Africa: JJA

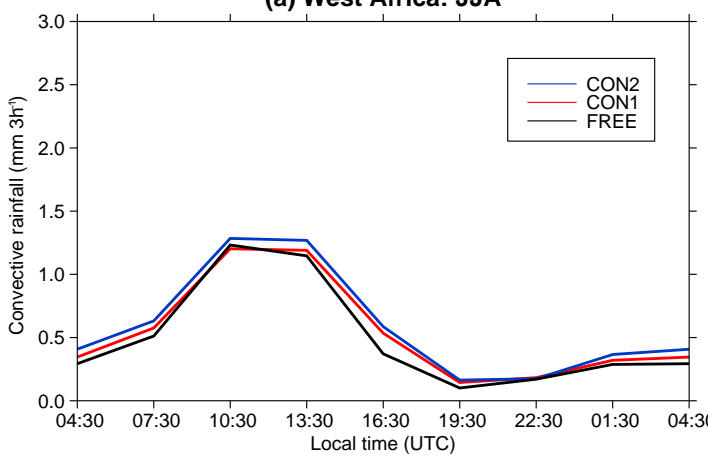

(c) Maritime Continent (Borneo): ANN

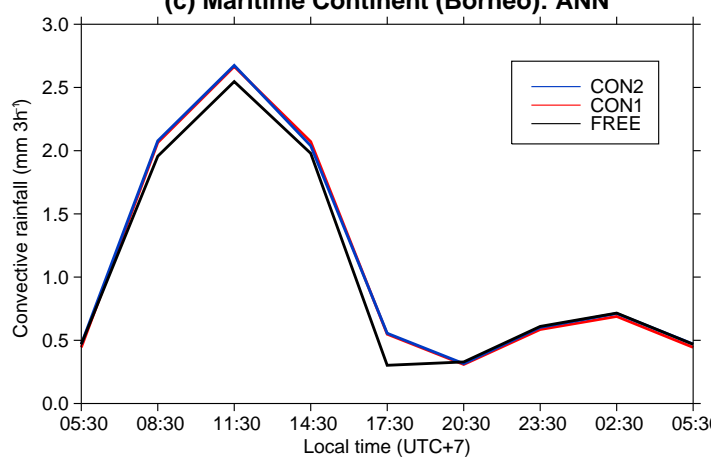

(b) North Australia: DJF

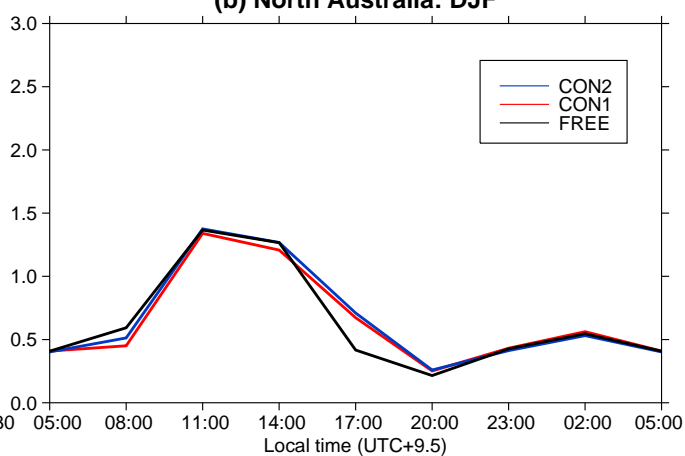

(d) Amazonia: ANN



Figure 5. Diurnal cycle of convective precipitation in the tropics $\left(\mathrm{mm} 3 \mathrm{~h}^{-1}\right.$ ) at (a) $0^{\circ} \mathrm{E}$ and $15^{\circ} \mathrm{N}$ (West Africa) in JJA, (b) $135^{\circ} \mathrm{E}$ and $15^{\circ} \mathrm{S}$ (northern Australia) in DJF, (c) $112.5^{\circ} \mathrm{E}$ and $0^{\circ} \mathrm{N}$ (Borneo, equatorial island) annual mean, and (d) $300^{\circ} \mathrm{E}$ and $0^{\circ} \mathrm{N}$ (Amazon, equatorial continental) annual mean.

latitudes (Fig. 3a). The largest difference in $T_{1.5}$ between CON1 and FREE $(-1.32 \mathrm{~K})$ occurs at $277.5^{\circ} \mathrm{E}\left(82.5^{\circ} \mathrm{W}\right)$ and $67.5^{\circ} \mathrm{N}$ (in northern Canada), and the anomaly is particularly pronounced between September and May (and particularly in December to February - not shown). It is hypothesized that the prescribed surface temperatures in the CON1 simulation may be changing the surface snow cover relative to FREE over the NH high latitudes.

To investigate this hypothesis, the snow mass at $277.5^{\circ} \mathrm{E}$ and $67.5^{\circ} \mathrm{N}$ during September, October, and November (SON) is plotted in Fig. 7a. The values for each individual day of SON are averaged over all 50 simulation years to give the mean time series of snow accumulation in FREE (solid line) and CON1 (dashed line) during that season (Fig. 7a). From approximately day 29, the CON1 simulation has (on average) more snow lying on the surface than FREE (Fig. 7a), which continues into boreal winter (not shown). The prescribed surface temperatures in CON1 therefore are causing more snow to accumulate relative to FREE, and the reason for this can be seen in Fig. 7b. The daily maximum surface temperature at $277.5^{\circ} \mathrm{E}$ and $67.5^{\circ} \mathrm{N}$ during SON in CON1 (black, solid line) is plotted in Fig. 7b. The day on which the maximum surface temperature drops below $0{ }^{\circ} \mathrm{C}$ is denoted by the dashed lines and corresponds with day 29 (as also marked in Fig. 7a). After this point, the surface temperature does not rise above the freezing point of water, and therefore the surface snow cannot melt away. Conversely, in many of the 50 realizations of SON in FREE (grey lines, Fig. 7b), the maximum surface temperatures remain above $0^{\circ} \mathrm{C}$ past day 29 of SON, and so the snow can still melt after this point. Therefore, due to prescribing the surface temperatures, snowmelt is typically prevented earlier in CON1 than FREE, and so snow amounts are, on average, higher in CON1 during the cold season, which causes $T_{1.5}$ to be systematically lower.

The lower values of $T_{1.5}$ within the Arctic Circle appear to cause a reduction in precipitation westward of Greenland and to the north-east of Asia; however, the differences in precipitation over the rest of the globe between CON1 and FREE are largely insignificant (Fig. 4a). Moreover, the differences in mean sea level pressure between CON1 and FREE are also largely insignificant (Fig. 6a). It appears that differences in $T_{1.5}$ between CON1 and FREE have relatively little impact on the global precipitation and circulation fields. Therefore the prescribed land surface temperature simulation (CON1) is broadly able to reproduce the climate of the original simulation (FREE) from which the land surface temperatures are derived. 
(a) CON1 - FREE

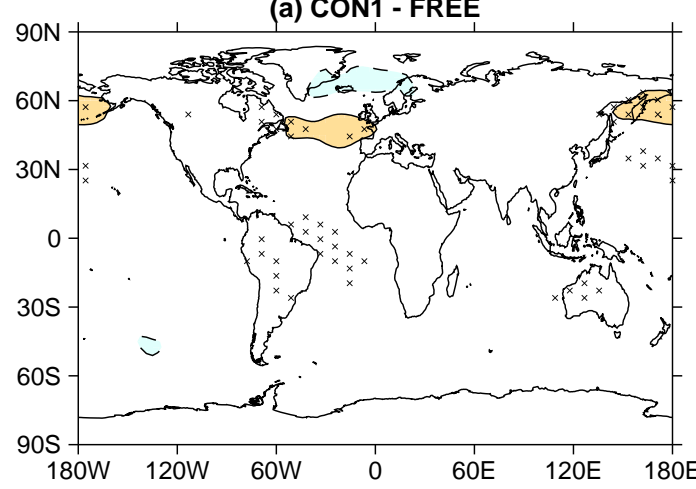

(c) ALL10K - CON1

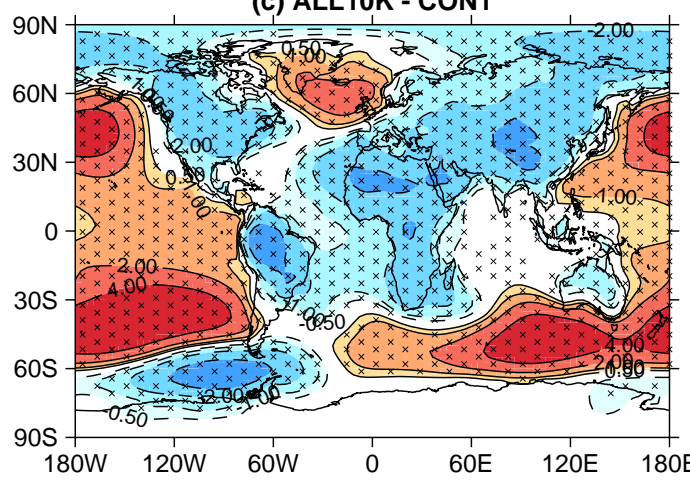

(e) MC10K - CON1

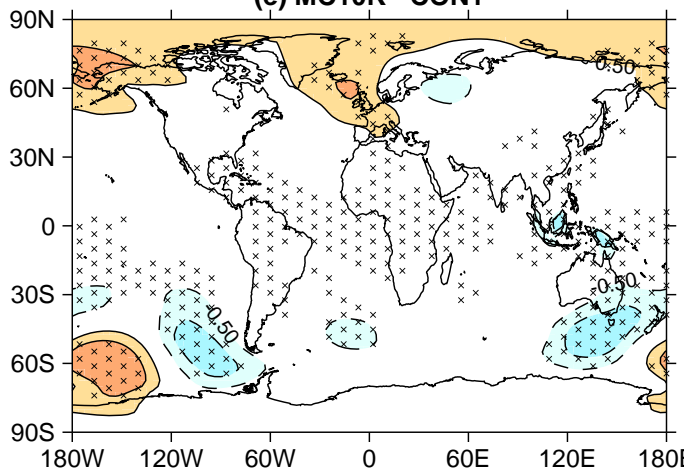

(g) AM10K - CON1

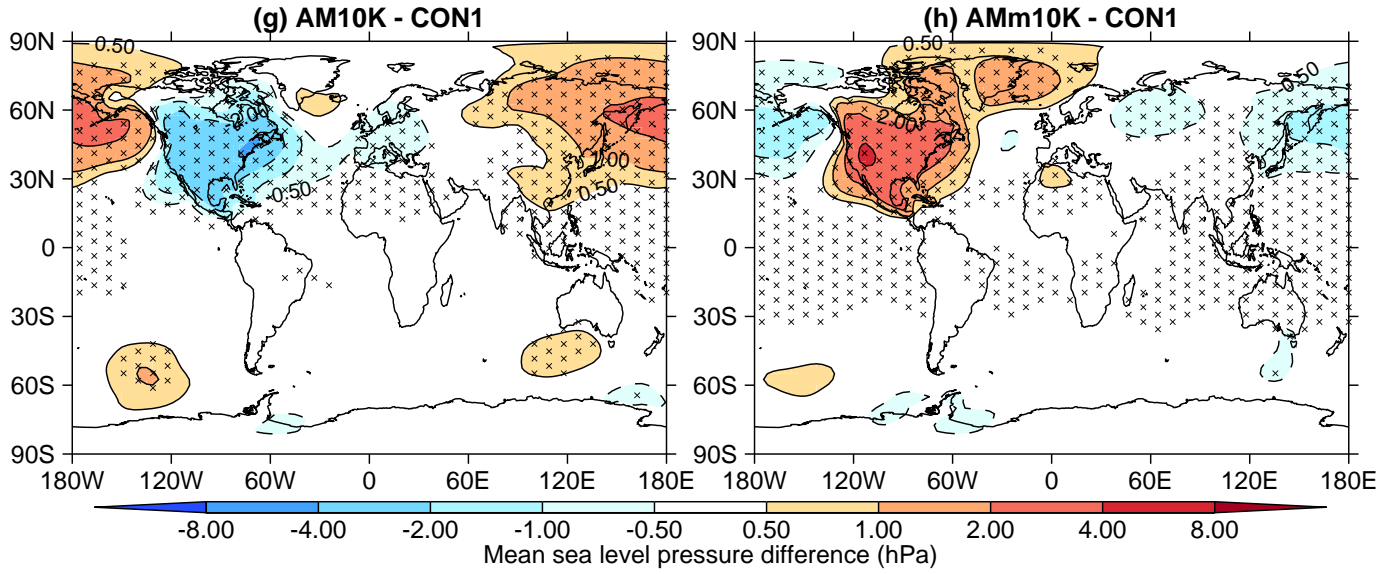

(b) CON2 - CON1

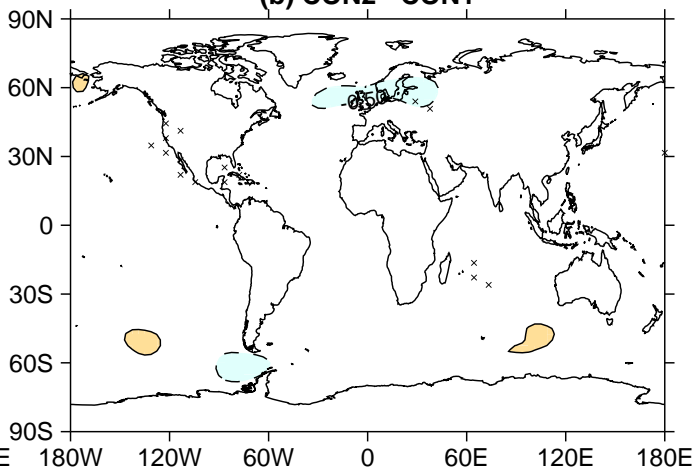

(d) Amaz. +10K - CON

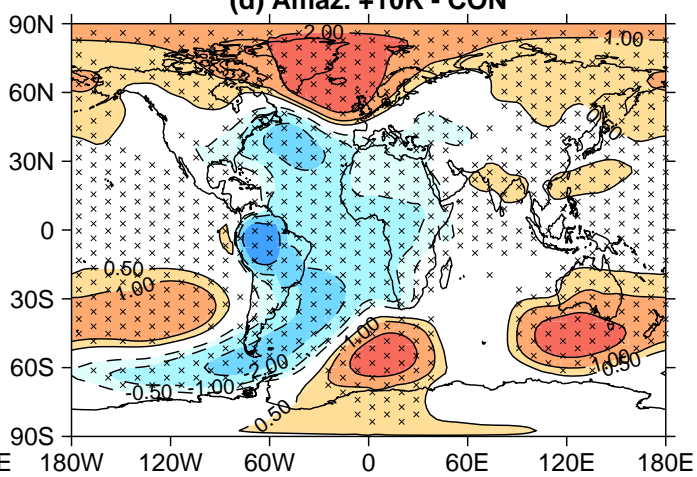

(f) AUS10K - CON1

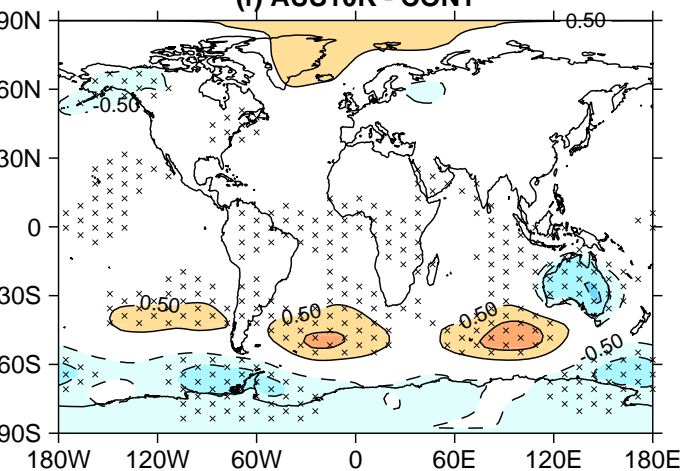

(h) AMm10K - CON1

Figure 6. Differences in annual mean, mean sea level pressure (hPa) for (a) CON1 - FREE, (b) CON2 - CON1, (c) ALL10K - CON1, (d) AMA10K - CON1, (e) MC10K - CON1, (f) AUS10K - CON1, (g) AM10K - CON1, and (h) AMm10K - CON1. Values of $p \leq 0.05$ are denoted with an $\mathrm{x}$. 


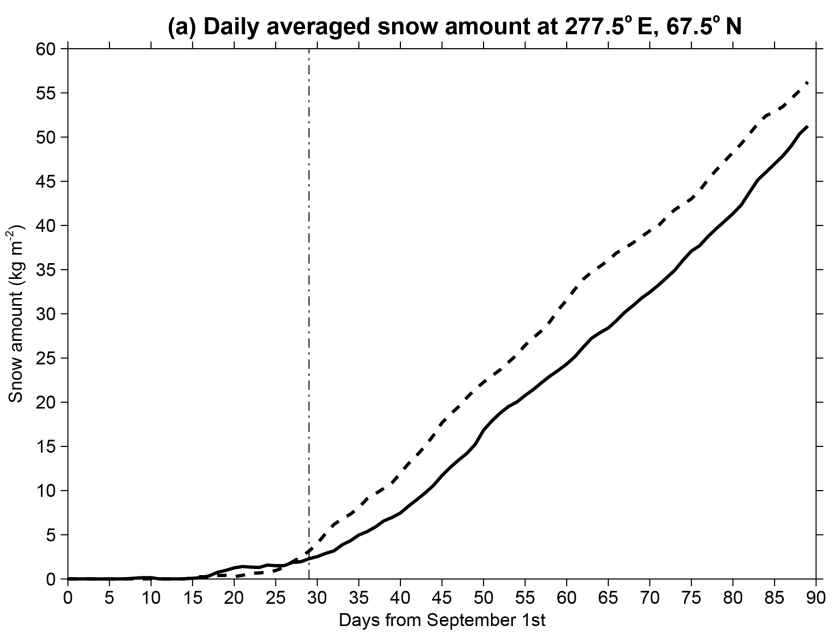

(b) Daily maximum ts at $277.5^{\circ} \mathrm{E}, 67.5^{\circ} \mathrm{N}$

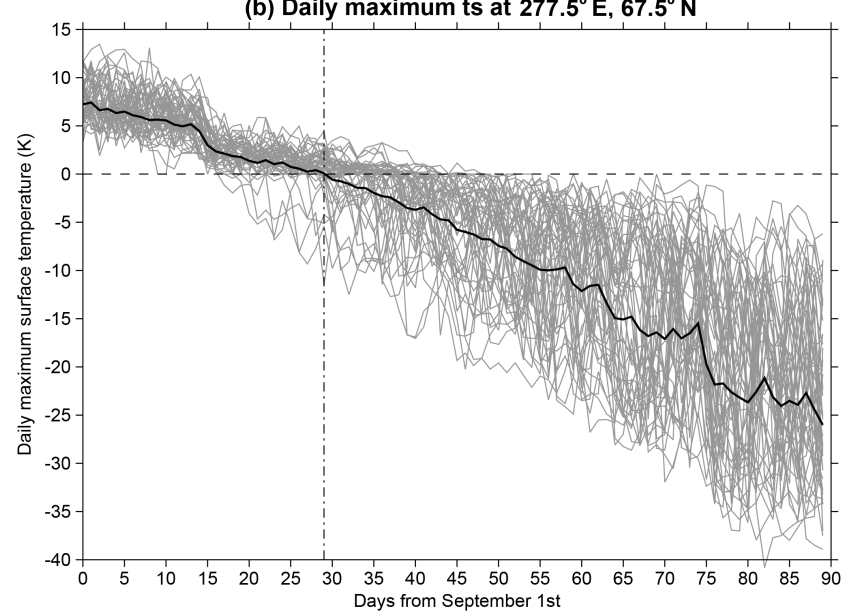

Figure 7. Time series of (a) mean daily snow amounts in SON averaged over 50 years of simulation in FREE (solid line) and CON1 (dashed line). (b) Time series of maximum daily surface temperatures during SON from all years in FREE (grey lines) and CON1 (solid black line).

\subsubsection{CON1 vs. CON2}

The differences in $T_{1.5}$ (Fig. 3b), precipitation (Fig. 4b), and mean sea level pressure (Fig. 6b) between CON2 and CON1 are climatologically indistinguishable. The climatological states of the modelled atmospheres in CON1 and CON2 are therefore not sensitive to changes in the initial conditions and show further that this model setup is reliable for other users to perform idealized simulations without the need to use the same initial conditions as this study.

\subsection{Temperature perturbation experiments}

\subsubsection{ALL10K}

Previous work by Chadwick et al. (2013b) shows that induced heating of the land surface causes an increase in tropical precipitation in GCM experiments with prescribed SSTs.
Nevertheless, in order to induce that surface warming, Chadwick et al. (2013b) either quadrupled $\mathrm{CO}_{2}$ concentrations or increased the solar constant; therefore, the surface temperature response to those perturbations would have been unknown until after the experiments were run. The method of prescribing surface temperatures shown in this study therefore presents an opportunity to assess the impact of increasing land surface temperatures - by a pre-determined quantity - on tropical (and global) precipitation in comparison to those of Chadwick et al. (2013b), who increase land surface temperatures indirectly.

An increase in precipitation over almost all tropical land surfaces can be seen in the ALL10K experiment (Fig. 4c). To first order, the changes in precipitation appear to be caused by enhanced convection over the land (uplift) and suppressed convection over the ocean (subsidence), which coincide with a reduction in MSLP (Figs. 4c and 6c) as suggested by Bayr and Dommenget (2013). Nonetheless, the pattern correlation between the differences in precipitation and MSLP in Figs. $4 \mathrm{c}$ and $6 \mathrm{c}$ is weak $(-0.20)$ and there are several regions where the MSLP and precipitation differences are the same sign (e.g. over the Atlantic and central Asia). Therefore MSLP may not be a good indicator of the changes in circulation that are causing the changes in precipitation.

The mean pressure vertical velocity at $500 \mathrm{hPa}\left(\omega_{500}\right)$ is plotted for CON1 in Fig. 8a with dashed lines indicating areas of climatological ascent and solid lines for subsidence. The same field is given for ALL10K in Fig. 8b (contours), with the difference in $\omega_{500}$ for ALL10K relative to CON1 overlaid (red indicating relative subsidence and blue relative ascent). There is a strengthening and expansion of the ascent regions over central-southern Africa, northern South America, the islands of the Maritime Continent, and northern Australia, with increased subsidence over the tropicalsub-tropical Atlantic, Indian Ocean and the ocean surrounding the Maritime Continent. Moreover, the pattern correlation between the $\omega_{500}$ anomalies in Fig. $8 \mathrm{~b}$ and the precipitation anomalies in Fig. 4 is -0.69 , which indicates that $\omega_{500}$ is a better indicator of the circulation-induced precipitation changes than the MSLP. These results also agree with the results of Chadwick et al. (2013a, b), who show that the spatial patterns of tropical precipitation response are also driven by circulation changes and not just the local thermodynamic influence (i.e. increased surface temperatures). While it should be expected that the largest changes in precipitation should be over the land (given the pattern of surface temperature increases), precipitation does not increase over all land grid points. This is most apparent over the Indian sub-continent where (to first order) the increased surface temperatures should enhance precipitation; however, the large-scale re-organization of the tropical circulation (seen in Fig. 8) results in positive differences in $\omega_{500}$ for ALL10K relative to CON1 over southern India, which would suppress precipitation. 


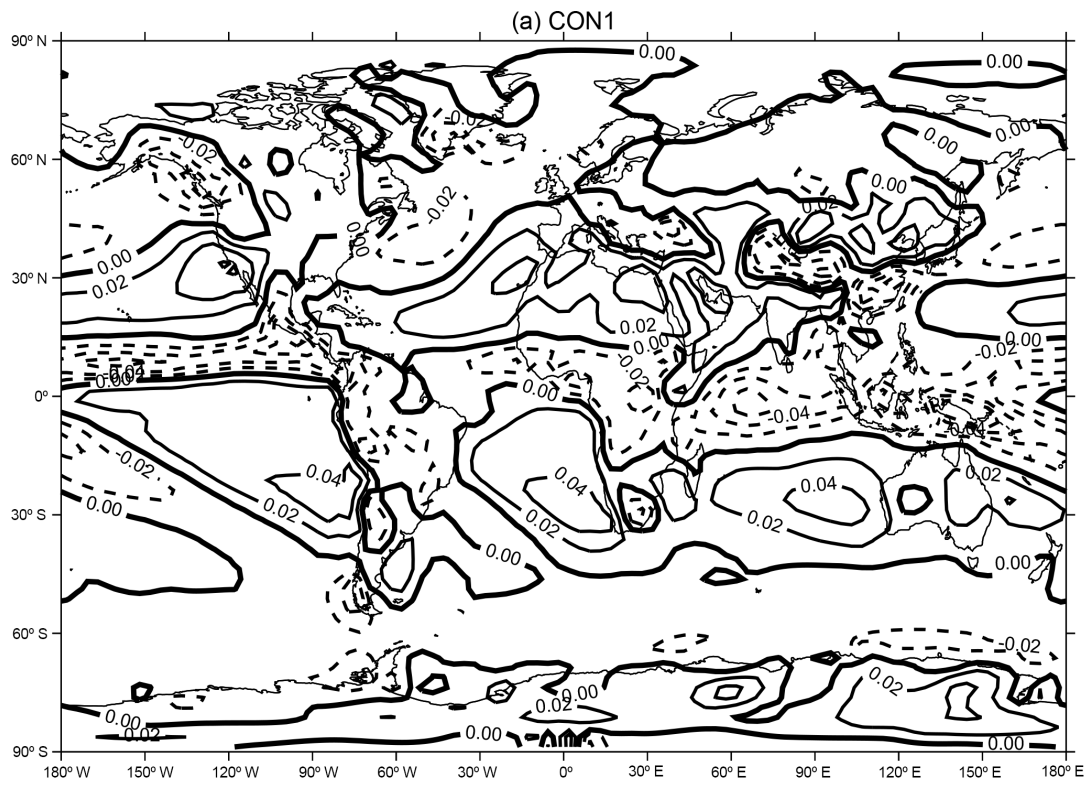

(b) ALL10K

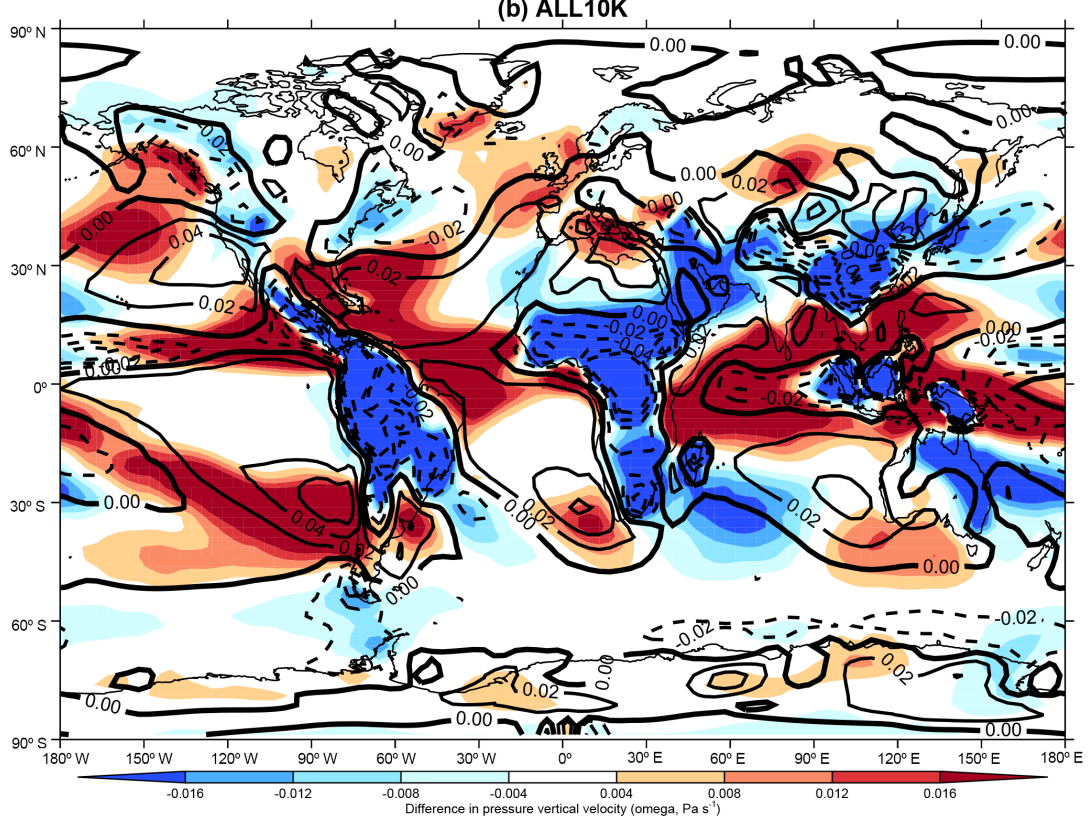

Figure 8. The climatological mean (averaged over all years of simulation) pressure vertical velocity at $500 \mathrm{hPa}\left(\omega_{500}, \mathrm{~Pa} \mathrm{~s}^{-1}\right)$ in the (a) $\mathrm{CON}_{1}$ and (b) ALL10K simulations. Solid lines indicate positive (subsidence) and dashed lines negative (uplift) values. Overlaid in (b) are the differences between ALL10K and CON1 where red shading indicates a positive difference and blue shading negative.

\subsubsection{Tropical experiments: AMA10K and MC10K}

In both the AMA10K and MC10K experiments, there is evidence of alternating $T_{1.5}$, precipitation, and MSLP anomalies emanating from the region of increased surface temperatures and extending into the mid-latitudes of both hemispheres (see Sect. 3). These $T_{1.5}$, precipitation, and MSLP anomalies that alternate in sign suggest that there are waves propagating away from the imposed tropical heat sources (Gill, 1980), which in this case are from increasing sur- face temperatures by $10 \mathrm{~K}$ and the resultant increase in latent heat release (inferred from the increase in precipitation; see Fig. 4d and e). Such a response is consistent with the modelling study of Hoskins and Karoly (1981) where lowlatitude diabatic heating can excite Rossby wave propagation into the high latitudes provided there was a background westerly flow. Moreover, Hoskins and Ambrizzi (1993) and Jin and Hoskins (1995) showed that the excitement of Rossby waves from a tropical source depends on the location of the diabatic heating and the background zonal flow in the tropics 
and mid-latitudes, which vary seasonally. In order to identify whether the $T_{1.5}$, precipitation, and MSLP features are associated with wave propagation away from the tropics, the characteristics of the upper-level atmospheric flow need to be considered. Hoskins and Karoly (1981) and Hoskins and Ambrizzi (1993) primarily focus on the $300 \mathrm{hPa}$ fields, which are also considered here for ease of comparison.

The differences in the zonal mean deviation of the $300 \mathrm{hPa}$ streamfunction (contours) for AMA10K and MC10K relative to CON1 are plotted in Fig. 9. The fields are timeaveraged annually (ANN), for December-February (DJF), and for June-August (JJA). The orange boxes denote the land areas where the surface temperature has been increased by $10 \mathrm{~K}$. In both the AMA10K and MC10K experiments (Fig. 9a and d), alternating positive and negative streamfunction anomalies can be seen emanating from the region of increased land surface temperatures and into the high latitudes of both hemispheres. The magnitudes of the streamfunction anomalies appear to be stronger in the AMA10K simulation than the MC10K simulation, which may be due to the smaller areal extent of the Maritime Continent islands and therefore their impact on the atmospheric circulation. Nevertheless, Hoskins and Karoly (1981) and Hoskins and Ambrizzi (1993) show that if the heating anomaly is located in background easterly flow, then this can suppress the development of waves that propagate towards higher latitudes. Regions where the $300 \mathrm{hPa}$ mean flow is negative (easterly) are stippled in blue in Fig. 9. The surface temperature perturbations in the $\mathrm{MC} 10 \mathrm{~K}$ experiment lie completely within a region of background easterly flow, whereas the AMA10K heating region extends into areas with background westerly flow in both hemispheres. Therefore the background atmospheric state is likely to be playing a role in weakening the teleconnections between the tropical convection and mid-latitude circulation in the MC10K experiment relative to AMA10K.

The importance of the location of the surface temperature perturbation relative to the background flow, rather than simply the areal extent of the heating source, is more obvious when the seasonal (DJF and JJA) averages are considered. In DJF (Fig. 9b and e), background easterly flow is located between $0-150^{\circ} \mathrm{E}$ and $5^{\circ} \mathrm{N}-10^{\circ} \mathrm{S}$ and over a small region of northern South America. As the AMA10K surface temperature perturbation zone extends into regions of westerly background flow in both hemispheres during DJF, there is strong wave activity in both the NH and SH (Fig. 9b), although the streamfunction anomalies are stronger in the winter hemisphere. As the Maritime Continent lies within climatological easterlies in the MC10K simulation, the waves appear weaker in the streamfunction field in both hemispheres, although the waves are still present (Fig. 9e).

In JJA, the Amazonian heating source lies entirely south of the band of background easterly flow at $300 \mathrm{hPa}$, and there is little wave activity apparent in the streamfunction field in the $\mathrm{NH}$ as a result (Fig. 9c). Moreover, there is a much broader band of background easterly flow northward of the Maritime
Continent heating source and subsequently there is no evidence of wave activity propagating into the NH high latitudes (Fig. 9f). There is however strong wave activity in the SH during JJA in both the AMA10K and MC10K experiments (Fig. 9c and f), where the background westerly flow adjacent to the region of increased surface temperatures allows for Rossby wave propagation into the higher latitudes. Therefore, based on the evidence given above, it is more likely to be the background atmospheric state, as opposed to the areal extent of the surface temperature perturbation, that is causing the stationary Rossby waves in each hemisphere. Nevertheless, the larger areal extent of the diabatic heating (and higher precipitation amounts) in AMA10K relative to $\mathrm{MC} 10 \mathrm{~K}$ is also likely to be an important factor in the different wave responses between those two simulations.

Overall, the circulation responses to both of these tropical heating sources are broadly consistent with the results of Hoskins and Karoly (1981), Hoskins and Ambrizzi (1993), and Jin and Hoskins (1995). Nevertheless, there are cases where the cross-equatorial meridional flow can allow Rossby wave propagation through easterly flow (as discussed in Schneider and Watterson, 1984; Watterson and Schneider, 1987; Zhao et al., 2015). For example, Zhao et al. (2015) show that wave sources in the summer hemisphere can excite wave activity in the winter hemisphere if the meridional flow is from the summer to the winter hemisphere. Therefore, the idealized GCM with prescribed land surface temperatures in this study is likely to be useful for running similar experiments that address all of these features (where easterlies do and do not act as a barrier to wave propagation).

\subsubsection{Sub-tropical experiment: AUS10K}

Previous work has shown that Australian rainfall has changed regionally over the last 60 years (Smith, 2004; Berry et al., 2011); however, there has only been one study that perturbed the local surface conditions over the continent in order to account for the changes (Wardle and Smith, 2004). Wardle and Smith (2004) decreased the land surface albedo by a factor of 4 over the whole of the Australian continent to induce an increase in surface temperature and cause an increase in monsoon rainfall. The AUS10K experiment (Table 1) now provides an opportunity to qualitatively compare the impact of directly increasing Australian land surface temperatures with an indirect method (i.e. reducing the surface albedo as in Wardle and Smith, 2004).

Precipitation increases are primarily in the north and east (Fig. 4f), which implies that the monsoon driven rainfall is responding the strongest (the largest changes occur in DJF not shown). Moreover, the increase in precipitation is primarily through increased convective precipitation, which suggests an increase in ascending air over the continent, which causes the MSLP to be lower over Australia (Fig. 6f). Reduced MSLP and increased monsoon rainfall also occur with decreased surface albedo (Wardle and Smith, 2004) and show 
(a) AMA10K - CON1 (ANN)

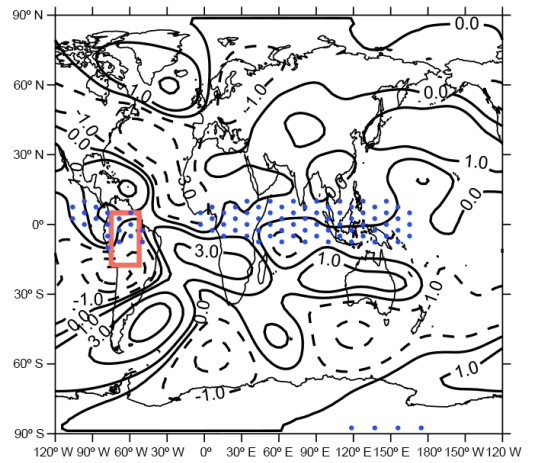

(b) AMA10K - CON1 (DJF)

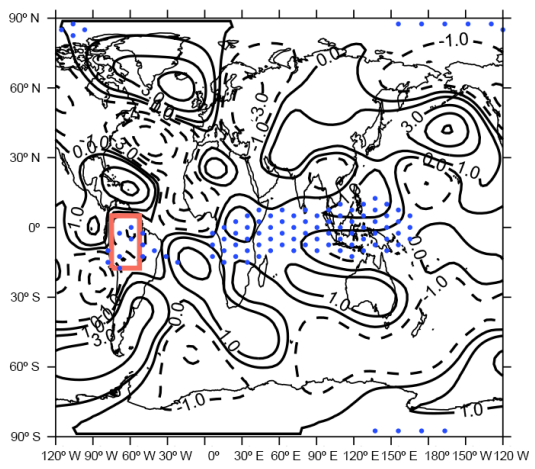

(c) AMA10K - CON1 (JJA)

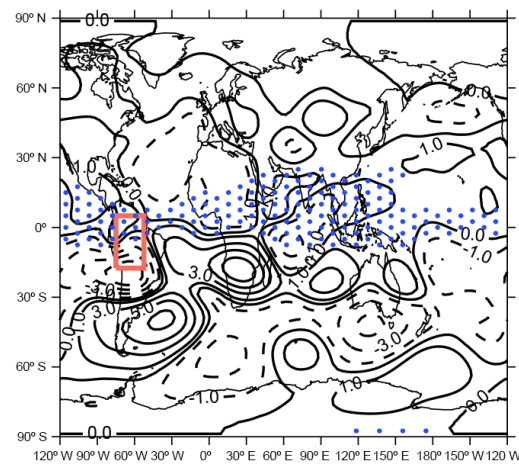

(d) MC10K - CON1 (ANN)

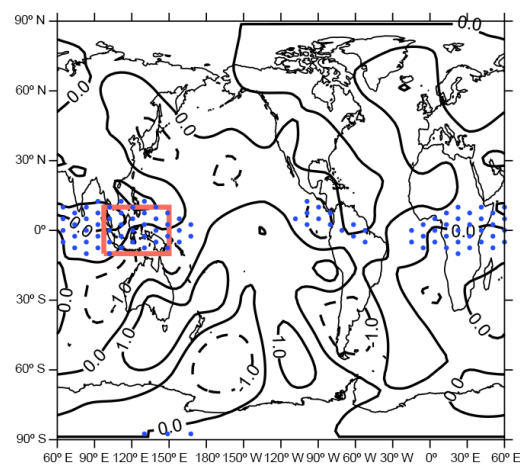

(e) MC10K - CON1 (DJF)

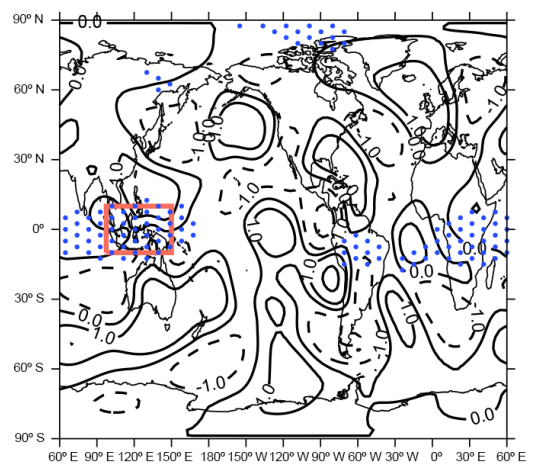

(f) MC10K - CON1 (JJA)

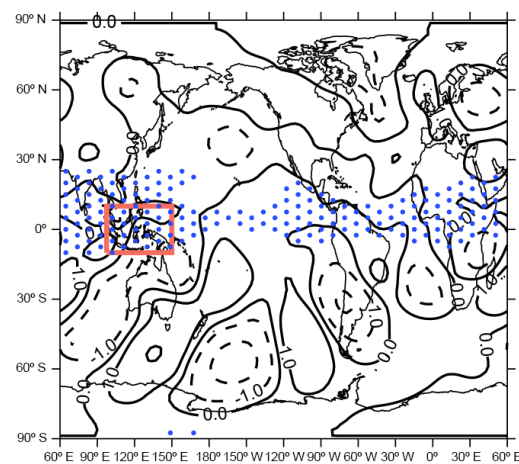

Figure 9. Differences in the deviation of the zonal mean streamfunction at $300 \mathrm{hPa}$ between AMA10K and CON1 for (a) annual mean, (b) DJF mean, and (c) JJA mean, and between MC10K and CON1 for (d) annual mean, (e) DJF mean, and (f) JJA mean (contours). Orange boxes indicate the area where the land surface temperatures were increased by $10 \mathrm{~K}$ in AMA10K (top row) and MC10K (bottom row). Grid points where the mean background zonal flow is easterly are stippled in blue.

the increased surface temperature in AUS10K is likely to be having a similar impact.

The change in convective rainfall over Australia also appears to be driving changes in the SH mid-latitude circulation. MSLP increases by $>0.5 \mathrm{hPa}$ over the Southern Ocean and decreases by a similar magnitude over the Antarctic (Fig. 6f). The MSLP changes are consistent with a transition towards the positive phase of the Southern Annular Mode (SAM, Thompson and Wallace, 2000). Moreover, there is also a poleward shift in the annual mean location of the $\mathrm{SH}$ mid-latitude jet (Fig. 10a), which is consistent with a more positive phase of SAM. The largest changes in the zonal wind occur in DJF (0.5-2.0 $\mathrm{m} \mathrm{s}^{-1}$, Fig. 10b) rather than JJA (typically $<0.5 \mathrm{~m} \mathrm{~s}^{-1}$, Fig. 10c), which coincides with the periods where the Australian monsoon is active and inactive, respectively.

Such an impact on the SAM was not discussed in Wardle and Smith (2004) and warrants further investigation - especially given that there has been a shift towards a more positive phase of the SAM in DJF over the last 60 years (Gillett et al., 2013). The majority of the trend towards a more positive SAM is attributed to SH stratospheric ozone depletion
(Arblaster and Meehl, 2006; Polvani et al., 2011); however, greenhouse gases also play a weaker role in in the positive trend in the SAM index, which may in part be caused by an increase in the SH meridional temperature gradient (Arblaster et al., 2011). Given that land surface temperatures are expected to increase more than SSTs from increasing atmospheric greenhouse gas concentrations (Sutton et al., 2007; Joshi et al., 2008; Dommenget, 2009), the model developed in this study could be used to understand the impact of the land-sea surface temperature contrast on large-scale modes of atmospheric variability (such as the SAM).

\subsubsection{North American experiments: AM10K and AMm10K}

Increasing (AM10K) and decreasing (AMm10K) the North American continental surface temperatures induce local decreases and increases in MSLP, respectively (Fig. $6 \mathrm{~g}$ and $\mathrm{h}$ ). Moreover, precipitation increases over most of North America in AM10K (except the central plains, Fig. 4g) and decreases in AMm10K (Fig. 4h) in response to the respective surface temperature perturbation. The atmospheric responses 
(a) Annual mean: AUS10K - CON1

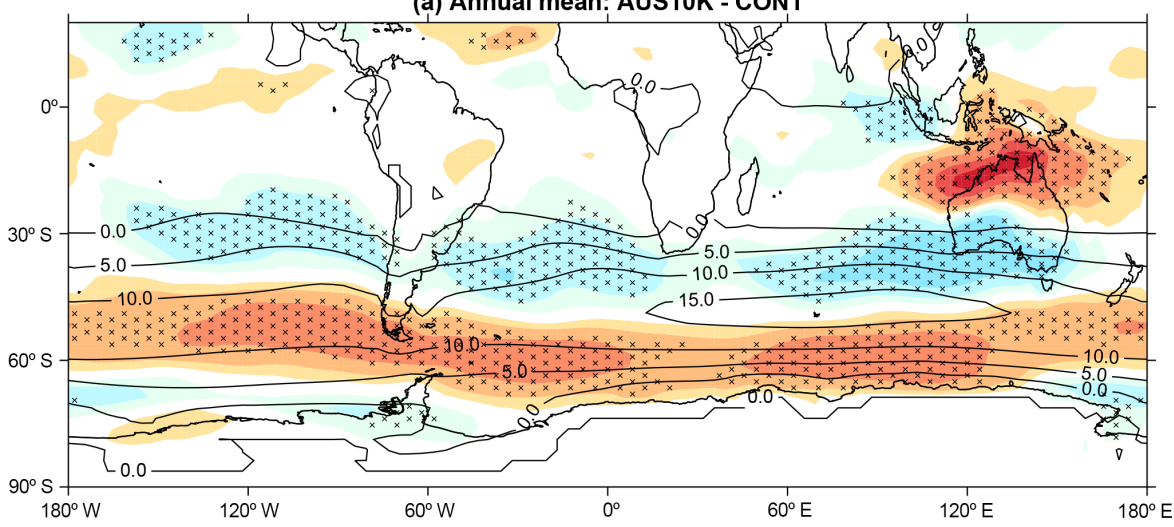

(b) DJF mean: AUS10K - CON1

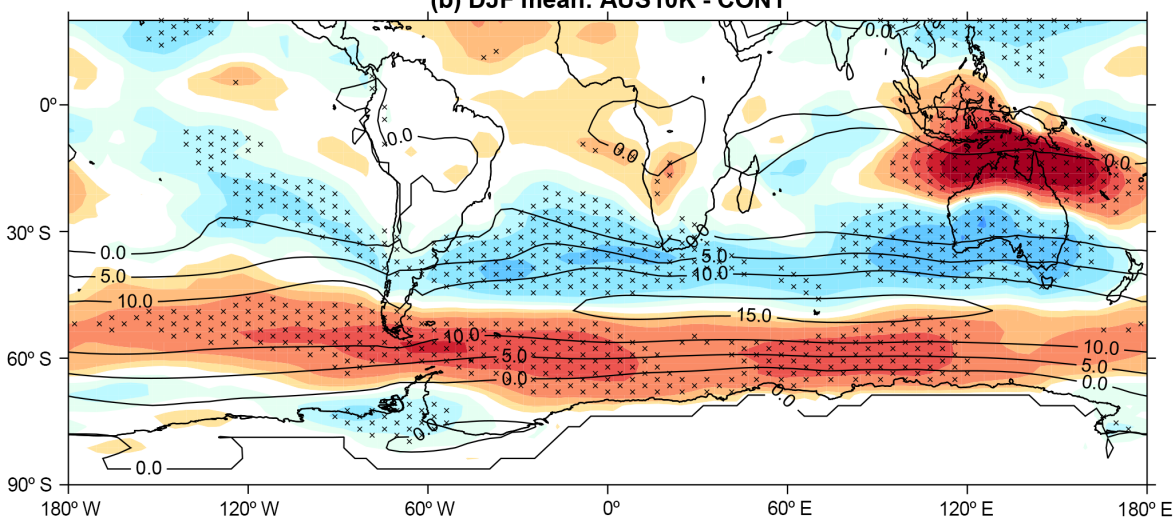

(c) JJA mean: AUS10K - CON1

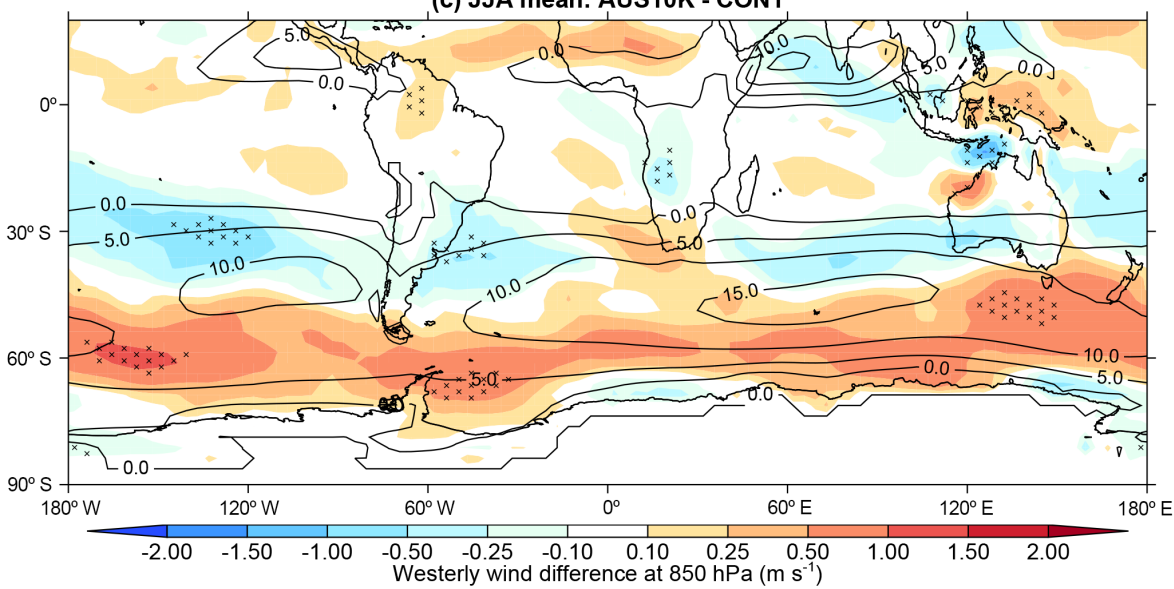

Figure 10. The difference in the $850 \mathrm{hPa}$ zonal flow $\left(\mathrm{m} \mathrm{s}^{-1}\right.$ ) in AUS10K relative to CON1 for the (a) annual mean, (b) DJF mean, and (c) JJA mean (shaded). Overlaid (solid contours) is the mean zonal flow in CON1 to highlight the location of the westerly jet at $850 \mathrm{hPa}$. Values of $p \leq 0.05$ are denoted with an $\mathrm{x}$

to the $\pm 10 \mathrm{~K}$ surface temperature perturbations over North America also appear to be of almost equal and opposing sign in each respective simulation, which suggests the circulation and precipitation respond in a linear way to the different surface temperature conditions.
The largest changes in precipitation occur in JJA (boreal summer, not shown) where the increased surface temperature (Fig. 11a) causes an increase in convective rainfall in AM10K (Fig. 11b) and vice versa for AMm10K (Fig. 11e and $\mathrm{f}$ ). It is also in JJA when the positive and negative anomalies in the annual mean $T_{1.5}$ over northern Asia and northern 
Africa (Fig. 3g and h) are at their strongest (Fig. 11a and e). Therefore, the rest of this section will focus on the changes in the JJA circulation in response to the surface temperature perturbations imposed on the North American continent.

Locally, the increased surface temperatures and induced convection act to decrease the surface MSLP in AM10K (relative to CON1), which can also be seen as a negative $850 \mathrm{hPa}$ geopotential height $\left(\mathrm{Zg}_{850}\right)$ anomaly over North America (Fig. 11c) and an associated anomalous cyclonic flow over the continent. Conversely, the $\mathrm{Zg}_{850}$ field is higher in AMm10K than CON1 over North America and is associated with anomalous anticyclonic flow (Fig. 11g) in response to the lower surface temperatures and suppressed convection. There are also large differences in the $\mathrm{Zg}_{850}$ and $850 \mathrm{hPa}$ wind field to the west of North America, with an anomalous anticyclone and positive $\mathrm{Zg}_{850}$ values over the North Pacific in AM10K (Fig. 11c) and negative $\mathrm{Zg}_{850}$ values and cyclonic flow in AMm10K (Fig. 11g).

Miyasaka and Nakamura (2005) show that the land-sea thermal contrast along the western coast of North America is important in causing the formation and maintenance of the Northern Hemisphere, summertime sub-tropical highpressure cell over the North Pacific. Miyasaka and Nakamura (2005) show that the increase in low-level potential temperatures from boreal spring to summer over the North American continent in July (and May) acts to increase cyclonic vorticity (cyclone stretching) over the continent, which strengthens the northerly flow along the western coast. Strengthening of the northerlies then increases the advection of polar air over the ocean, enhances evaporation from the ocean surface, and encourages the development marine stratocumulus, which all act to reduce SSTs. The cooling of the air column causes subsidence (visible at $500 \mathrm{hPa}$; see Fig. 8d in Miyasaka and Nakamura, 2005) and enhances the anticyclonic circulation (vortex compression) within the sub-tropical high-pressure cell over the ocean and strengthens the northerly flow and subsidence further.

Interestingly, the differences in circulation in Fig. 11c are qualitatively very similar to those produced by Miyasaka and Nakamura (2005), which suggests that increasing North American surface temperatures by $10 \mathrm{~K}$ may result in a strengthening of the Pacific sub-tropical high-pressure cell. To illustrate this further, the values of $\omega_{500}$ from CON1 (black solid and dashed lines) and the difference between AM10K and CON1 (coloured shading) are plotted in Fig. 11d. The largest increases in subsidence (red shading) at $500 \mathrm{hPa}$ occur over the centre and to the north of the maximum subsidence in CON1 (Fig. 11d), which may indicate a strengthening and northward shift of the summertime highpressure cell. Conversely, the opposite circulation anomalies occur in the AMm10K simulation (and with very similar magnitude), which suggests that the same process may be reversed by decreasing North American land surface temperatures (also seen in the $\omega_{500}$ field, Fig. $11 \mathrm{~h}$ ). It is therefore likely that increasing or decreasing the North American land surface temperatures in ACCESS may act to enhance or weaken the strength of the Pacific sub-tropical high-pressure cell (given that SSTs in the AM10K simulation do not respond to and feed back on the atmospheric circulation in the way described in Miyasaka and Nakamura, 2005). These results therefore indicate that this version of ACCESS (with prescribed land surface temperatures) may be useful for investigating the impact of regional land-sea thermal contrasts on the location and strength of the summertime sub-tropical high-pressure cells, for example.

\section{Conclusions and further applications}

The aims of this paper are to present a method of prescribing land surface temperatures in a GCM and show that the resulting simulated climate state is comparable with a simulation that uses freely evolving land temperatures. Furthermore, the study has shown that the atmospheric responses to land surface temperature perturbations broadly agree with physical processes noted in previous studies using idealized GCM simulations. The main conclusions from this study therefore are the following.

- It is possible to prescribe land surface temperatures in ACCESS (excluding Antarctica) and produce a simulated atmospheric state similar to that of a freely varying land temperature simulation.

- The diurnal cycle in tropical convection is maintained in the prescribed simulations.

- Increasing all land surface temperatures by $10 \mathrm{~K}$ generally increases (decreases) precipitation over the land (ocean).

- Regional increases in tropical surface temperatures may cause the formation of stationary Rossby waves that are dependent on the location of the heat source and the background state atmospheric zonal flow.

- Increasing the surface temperatures over the Australian continent causes an increase in monsoon rainfall and also acts to shift the SH mid-latitude westerlies poleward.

- Increasing and decreasing the land surface temperatures over North America act to either strengthen (increasing land temperatures) or weaken (reducing land temperatures) the North Pacific summertime high-pressure cell.

The experiments in this study showcase some specific examples of the potential applications for simulations with prescribed land surface temperatures. Further experiments/applications that could be developed include the following. 
(a) JJA AM10K $T_{1.5}$

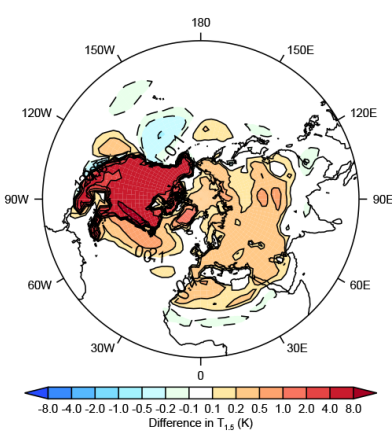

(b) JJA AM10K convective rainfall

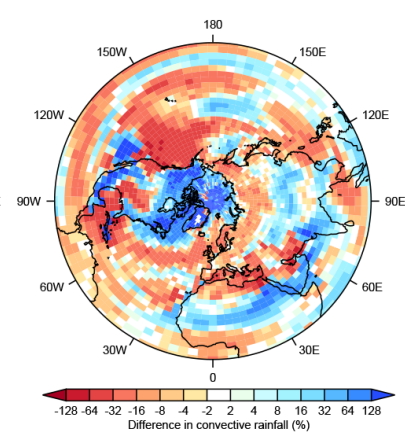

(c) JJA AM10K $850 \mathrm{hPa} \mathrm{Zg}$ and wind

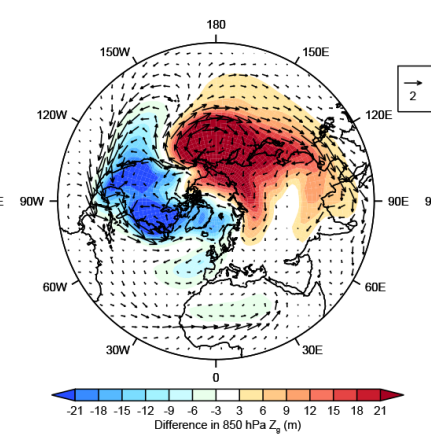

(d) JJA AM10K $500 \mathrm{hPa}$ omega

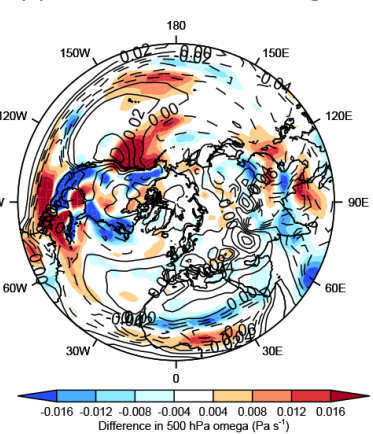

(e) JJA AMm10K $\mathrm{T}_{1.5}$

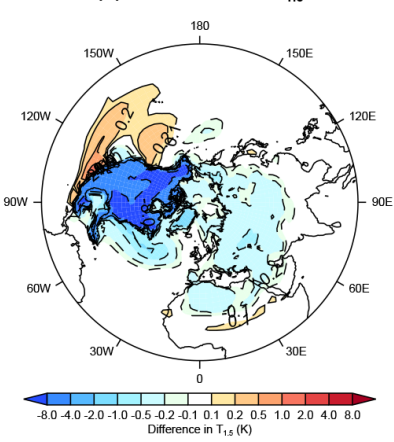

(f) JJA AMm10K convective rainfall

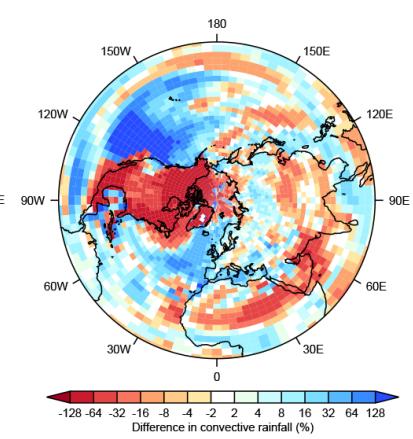

(g) JJA AMm10K $850 \mathrm{hPa} \mathrm{Zg}$ and wind

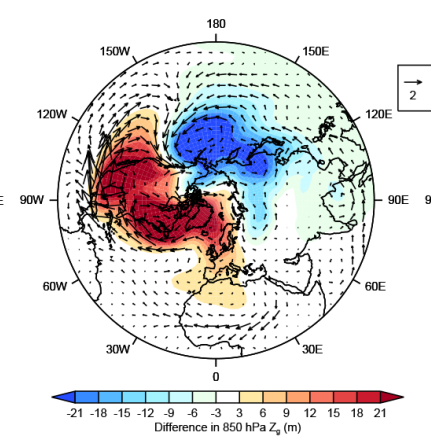

(h) JJA AMm10K $500 \mathrm{hPa}$ omega

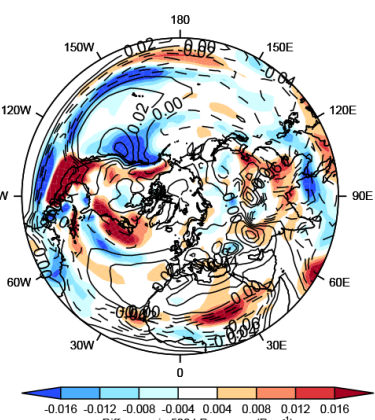

Figure 11. The JJA-mean differences between AM10K and CON1 simulations for (a) $T_{1.5}(\mathrm{~K})$, (b) convective precipitation (\%), (c) $850 \mathrm{hPa}$ geopotential height $(\mathrm{m})$ and wind field $\left(\mathrm{m} \mathrm{s}^{-1}\right)$, and $(\mathbf{d})$ the $500 \mathrm{hPa}$ pressure vertical velocity $\left(\omega_{500}, \mathrm{~Pa} \mathrm{~s}^{-1}\right.$, shaded) with the JJA-mean $\omega_{500}$ from CON1 overlaid (solid/dashed lines for positive/negative $\omega_{500}$ ). The JJA-mean differences between AMm10K and CON1 simulations for (e) $T_{1.5}(\mathrm{~K})$, (f) convective precipitation $(\%),(\mathbf{g}) 850 \mathrm{hPa}$ geopotential height (m) and wind field (m s$\left.{ }^{-1}\right)$, and (h) $\omega_{500}\left(\mathrm{~Pa} \mathrm{~s}{ }^{-1}\right.$, shaded) with the JJA-mean $\omega_{500}$ from CON1 overlaid (solid/dashed lines for positive/negative $\omega_{500}$ ).

1. Develop prescribed land surface temperature simulations that are compatible with the Community Atmosphere Biosphere Land Exchange (CABLE, Kowalczyk et al., 2013) and the Joint UK Land Environment Simulator (JULES, Best et al., 2011) models. The CABLE and JULES models are used in the latest versions of ACCESS and the MetUM GCMs, and the development of the simulations described in this study (i.e. using MOSES) should allow this method to be applicable to both of those modules.

2. Remove the soil temperature and soil moisture constraints. This will allow the soil moisture to respond freely to the imposed surface temperature field, which could have an impact on the modelled climate. For example, the circulation response in the ALL10K experiment may not be as strong once the local moisture supply for land-based convection has been evaporated away.

3. The adjusted radiative forcing has previously been calculated in simulations with prescribed SSTs that allow the atmosphere and land surface to respond freely to changes in $\mathrm{CO}_{2}$ (for examples see Andrews et al., 2012; Hansen et al., 2005). Nevertheless, Andrews et al. (2012) state that "Land temperatures can, for example, respond in fixed SST experiments. This gives rise to a global temperature increase that may cause circulation changes and other responses that affect the radiation balance", which presents a limitation to their analysis. Shine et al. (2003) show that the radiative forcings caused by $\mathrm{CO}_{2}$, aerosol, and ozone perturbations in simulations with both prescribed land and sea surface temperatures were an "excellent indicator of the surface temperature response" in parallel simulations using a mixed-layer ocean and freely varying land surface temperatures. Therefore, the ACCESS simulation with prescribed surface temperatures could be used for calculating the radiative forcing of $\mathrm{CO}_{2}$ and aerosol in the same way as Shine et al. (2003) and minimize the circulation feedbacks noted in Andrews et al. (2012).

4. AMIP simulations with perturbed SSTs (e.g. uniform increase in global SST by $4 \mathrm{~K}$ - AMIP4K) and greenhouse gases (quadrupled $\mathrm{CO}_{2}$ with prescribed AMIP SST - AMIP4 $\left.\mathrm{XCO}_{2}\right)$ are available in the CMIP5 
archive; however, the simulations developed in this paper could be used to develop an AMIP simulation with all surface temperatures increased uniformly by $4 \mathrm{~K}$ (e.g. AMIP4K $\mathrm{K}_{\mathrm{all}}$ ) with and without $\mathrm{CO}_{2}$ perturbations. Furthermore, there is also the potential for running coupled atmosphere-dynamical ocean simulations with prescribed land surface temperatures (reverse AMIP i.e. freely evolving ocean, prescribed land). Such simulations would reveal the impact of coupled oceanatmosphere circulation errors that result from biases in the representation of land surface temperatures.

5. Three-hourly surface temperature data are available from other CMIP5 models (apart from just ACCESS). Therefore, given the method described in this paper, those other models' surface temperature fields could be applied to ACCESS in order to identify whether the circulation biases in individual CMIP5 models are driven by errors in their surface temperatures (i.e. if circulation errors are surface temperature driven, then they should occur when applied to ACCESS).

6. Instead of holding the surface temperature to a fixed value, the approach can be altered by adding a flux correction term to the surface temperature tendency equation (Sausen et al., 1988). This is a common approach in coupled GCM development to correct SSTs in simplified or biased ocean models (for example see Collins et al., 2006). Such a method would allow the flux correction to be applied to the full global surface (and not just the ocean-atmosphere interface).

While this list is not exhaustive, it presents some logical steps forward for further testing and development.

\section{Code availability}

The model source code for ACCESS is not publicly available; however, more information can be found through the ACCESS-wiki at https://accessdev.nci.org.au/trac/wiki/ access. Any registered ACCESS users who wish to gain access to the source code described in this paper can do so from https://access-svn.nci.org.au/svn/um/branches/dev/ dxa565/src_presT_reg/src@9826.

Acknowledgements. This project was funded by the ARC Centre of Excellence for Climate System Science (CE110001028). The ACCESS simulations were undertaken with the assistance of the resources from the National Computational Infrastructure (NCI), which is supported by the Australian Government.

Edited by: J. Kala
References

Ackerley, D., Berry, G., Jakob, C., and Reeder, M. J.: The roles of diurnal forcing and large-scale moisture transport for initiating rain over north-west Australia in a GCM, Q. J. Roy. Meteor. Soc., 140, 2515-2526, doi:10.1002/qj.2316, 2014.

Ackerley, D., Berry, G., Jakob, C., Reeder, M. J., and Schwendike, J.: Summertime precipitation over northern Australia in AMIP simulations from CMIP5, Q. J. Roy. Meteor. Soc., 141, 17531768, doi:10.1002/qj.2476, 2015.

Andrews, T., Gregory, J. M., Webb, M. J., and Taylor, K. E.: Forcing, feedbacks and climate sensitivity in CMIP5 coupled atmosphere-ocean climate models, Geophys. Res. Lett., 39, 109712, doi:10.1029/2012GL051607, 2012.

Arblaster, J. M. and Meehl, G. A.: Contributions of External Forcings to Southern Annular Mode Trends, J. Climate, 19, 2896 2905, 2006.

Arblaster, J. M., Meehl, G. A., and Karoly, D. J.: Future climate change in the Southern Hemisphere: Competing effects of ozone and greenhouse gases., Geophys. Res. Lett., 38, L02701, doi:10.1002/qj.2476, 2011.

Bayr, T. and Dommenget, D.: The tropospheric land-sea warming contrast as the driver of tropical sea level pressure changes, J. Climate, 26, 1387-1402, 2013.

Berry, G., Reeder, M. J., and Jakob, C.: Physical Mechanisms Regulating Summertime Rainfall over Northwestern Australia, J. Climate, 24, 3705-3717, 2011.

Best, M. J., Cox, P. M., and Warrilow, D.: Determining the optimal soil temperature scheme for atmospheric modelling applications, Bound.-Lay. Meteorol., 114, 111-142, 2005.

Best, M. J., Pryor, M., Clark, D. B., Rooney, G. G., Essery, R. L. H., Ménard, C. B., Edwards, J. M., Hendry, M. A., Porson, A., Gedney, N., Mercado, L. M., Sitch, S., Blyth, E., Boucher, O., Cox, P. M., Grimmond, C. S. B., and Harding, R. J.: The Joint UK Land Environment Simulator (JULES), model description Part 1: Energy and water fluxes, Geosci. Model Dev., 4, 677-699, doi:10.5194/gmd-4-677-2011, 2011.

Bi, D., Dix, M., Marsland, S. J., O'Farrell, S., Rashid, H. A., Uotila, P., Hirst, A. C., Golebiewski, E. K. M., Sullivan, A., Yan, H., Hannah, N., Franklin, C., Sun, Z., Vohralik, P., Watterson, I., Zhou, Z., Fiedler, R., Collier, M., Ma, Y., Noonan, J., Stevens, L., Uhe, P., Zhu, H., Griffies, S. M., Hill, R., Harris, C., and Puri, K.: The ACCESS coupled model: description, control climate and evaluation, Aust. Meteorol. Ocean. J., 63, 41-64, 2013.

Bony, S., Webb, M., Bretherton, C., Klein, S., Siebesma, P., Tselioudis, G., and Zhang, M.: CFMIP: Towards a better evaluation and understanding of clouds and cloud feedbacks in CMIP5 models, CLIVAR Exchanges, 56, 20-24, 2011.

Chadwick, R., Boutle, I., and Martin, G. M.: Spatial patterns of precipitation change in CMIP5: Why the rich do not get richer in the tropics, J. Climate, 26, 3803-3822, doi:10.1175/JCLI-D-1200543.1, 2013a.

Chadwick, R., Good, P., Andrews, T., and Martin, G. M.: Surface warming patterns drive tropical rainfall pattern responses to $\mathrm{CO}_{2}$ forcing on all timescales, Geophys. Res. Lett., 41, 610-615, doi:10.1002/2013GL058504, 2013b.

Chou, C.: Land-sea heating contrast in an idealised Asian summer monsoon, Clim. Dynam., 21, 11-25, doi:10.1007/s00382-0030315-7, 2003. 
Collins, M., Booth, B. B. B., Harris, G. R., Murphy, J. M., Sexton, D. M. H., and Webb, M. J.: Towards quantifying uncertainty in transient climate change, Clim. Dynam., 27, 127-147, 2006.

Collins, M., Knutti, R., Arblaster, J., Dufresne, J.-L., Fichefet, T., Friedlingstein, P., Gao, X., Gutowski, W., Johns, T., Krinner, G., Shongwe, M., Tebaldi, C., Weaver, A., and Wehner, M.: in: Climate Change 2013: The Physical Science Basis. Contribution of Working Group I to the Fifth Assessment Report of the Intergovernmental Panel on Climate Change, chap. Long-term Climate Change: Projections, Commitments and Irreversibility, Cambridge University Press, Cambridge, United Kingdom and New York, NY, USA, edited by: Stocker, T. F., Qin, D., Plattner, G.-K., Tignor, M., Allen, S. K., Boschung, J., Nauels, A., Xia, Y., Bex, V., and Midgley, P. M., 2013.

Cox, P. M., Betts, R. A., Bunton, C. B., Essery, R. L. H., Rowntree, P. R., and Smith, J.: The impact of new land surface physics on the GCM simulation of climate and climate sensitivity, Clim. Dynam., 15, 183-203, 1999.

Dai, A.: Precipitation Characteristics in Eighteen Coupled Climate Models, J. Climate, 19, 4605-4630, 2006.

Dai, A. and Trenberth, K. E.: The Diurnal Cycle and Its Depiction in the Community Climate System Model, J. Climate, 17, 930-951, 2004.

Dirnmeyer, P. A., Cash, B. A., Kinter III, J. L., Jung, T., Marx, L., Satoh, M., Stan, C., Tomita, H., Towers, P., Wedi, N., Achuthavarier, D., Adams, J. M., Altshuler, E. L., Huang, B., Jin, E. K., and Manganello, J.: Simulating the diurnal cycle of rainfall in global climate models: resolution versus parameterization, Clim. Dynam., 39, 399-418, 2012.

Dommenget, D.: The ocean's role in continental climate variability and change, J. Climate, 22, 4939-4952, 2009.

Dong, B. and Sutton, R.: Dominant role of greenhouse-gas forcing in the recovery of Sahel rainfall, Nature Climate Change, 5, 757760, doi:10.1038/nclimate2664, 2015.

Essery, R., Best, M. J., and Cox, P. M.: Hadley Centre Technical Note 30: MOSES2.2 technical documentation, Tech. rep., United Kingdom Met Office, http://www.metoffice.gov.uk/media/pdf/9/ j/HCTN_30.pdf (last access: 3 June 2016), 2001.

Essery, R. L. H., Best, M. J., Betts, R. A., Cox, P. M., and Taylor, C. M.: Explicit Representation of Subgrid Heterogeneity in a GCM Land Surface Scheme, J. Hydrometeorol., 4, 530-543, 2003.

Frauen, C., Dommenget, D., Tyrrell, N., Rezny, M., and Wales, S.: Analysis of the Nonlinearity of El Niño Southern Oscillation Teleconnections, J. Climate, 27, 6225-6244, 2014.

Gates, W. L.: AMIP: The atmospheric model intercomparison project, B. Am. Meteorol. Soc., 73, 1962-1970, 1992.

Gates, W. L., Boyle, J. S., Covey, C., Dease, C. G., Doutriaux, C. M., Drach, R. S., Florino, M., Gleckler, P. J., Hnilo, J. J., Marlais, S. M., Phillips, T. J., Potter, G. L., Santer, B. D., Sperber, K. R., Taylor, K. E., and Williams, D. N.: An Overview of the Results of the Atmospheric Model Intercomparison Project (AMIP I), B. Am. Meteorol. Soc., 80, 29-55, 1999.

Gill, A. E.: Some simple solutions for heat-induced tropical circulation, Q. J. Roy. Meteor. Soc., 106, 447-462, 1980.

Gillett, N. P., Fyfe, J. C., and Parker, D. E.: Attribution of observed sea level pressure trends to greenhouse gas, aerosol, and ozone changes, Geophys. Res. Lett., 40, 2302-2306, 2013.
The HadGEM2 Development Team: G. M. Martin, Bellouin, N., Collins, W. J., Culverwell, I. D., Halloran, P. R., Hardiman, S. C., Hinton, T. J., Jones, C. D., McDonald, R. E., McLaren, A. J., O'Connor, F. M., Roberts, M. J., Rodriguez, J. M., Woodward, S., Best, M. J., Brooks, M. E., Brown, A. R., Butchart, N., Dearden, C., Derbyshire, S. H., Dharssi, I., Doutriaux-Boucher, M., Edwards, J. M., Falloon, P. D., Gedney, N., Gray, L. J., Hewitt, H. T., Hobson, M., Huddleston, M. R., Hughes, J., Ineson, S., Ingram, W. J., James, P. M., Johns, T. C., Johnson, C. E., Jones, A., Jones, C. P., Joshi, M. M., Keen, A. B., Liddicoat, S., Lock, A. P., Maidens, A. V., Manners, J. C., Milton, S. F., Rae, J. G. L., Ridley, J. K., Sellar, A., Senior, C. A., Totterdell, I. J., Verhoef, A., Vidale, P. L., and Wiltshire, A.: The HadGEM2 family of Met Office Unified Model climate configurations, Geosci. Model Dev., 4, 723-757, doi:10.5194/gmd-4-723-2011, 2011.

Hansen, J., Sato, M., Ruedy, R., Nazarenko, L., Lacis, A., Schmidt, G. A., Russell, G., Aleinov, I., Bauer, M., Bauer, S., Bell, N., Cairns, B., Canuto, V., Chandler, M., Cheng, Y., Del Genio, A., Faluvegi, G., Fleming, E., Friend, A., Hall, T., Jackman, C., Kelley, M., Kiang, N., Koch, D., Lean, J., Lerner, J., Lo, K., Menon, S., Miller, R., Minnis, P., Novakov, T., Oinas, V., Perlwitz, J., Perlwitz, J., Rind, D., Romanou, A., Shindell, D., Stone, P., Sun, S., Tausnev, N., Thresher, D., Wielicki, B., Wong, T., Yao, M., and Zhang, S.: Efficacy of climate forcings, J. Geophys. Res., 110, d18104, doi:10.1029/2005JD005776, 2005.

Harrison, S. P., Bartlein, P. J., Brewer, S., Prentice, I. C., Boyd, M., Hessler, I., Holmgren, K., Izumi, K., and Willis, K.: Climate model benchmarking with glacial and mid-Holocene climates, Clim. Dynam., 43, 671-688, 2014.

Hoskins, B. J. and Ambrizzi, T.: Rossby wave propagation on a realistic longitudinally varying flow, J. Atmos. Sci., 50, 1661-1671, 1993.

Hoskins, B. J. and Karoly, D. J.: The steady linear response of a spherical atmosphere to thermal and orographic forcing, J. Atmos. Sci., 38, 1179-1196, 1981.

Jin, F. and Hoskins, B. J.: The direct response to tropical heating in a baroclinic atmosphere, J. Atmos. Sci., 52, 307-319, 1995.

Joshi, M. M., Gregory, J. M., Webb, M. J., Sexton, D. M. H., and Johns, T. C.: Mechanisms for the land/sea warming contrast exhibited by simulations of climate change, Clim. Dynam., 30, 455-465, 2008.

Kowalczyk, E. A., Stevens, L., Law, R. M., Dix, M., Wang, Y. P., Harman, I. N., Haynes, K., Srbinovsky, J., Pak, B., and Ziehn, T.: The land surface model component of ACCESS: description and impact on simulated surface climatology, Aust. Meteorol. Ocean. J., 63, 65-82, 2013.

Kowalczyk, E. A., Stevens, L. E., Law, R. M., Harman, I. N., Dix, M., Franklin, C. N., and Wang, Y.-P.: The impact on the surface climatology from changing the land surface scheme in the ACCESS(v1.0/1.1) climate model, Geosci. Model Dev. Discuss., doi:10.5194/gmd-2016-35, in review, 2016.

Miyasaka, T. and Nakamura, H.: Structure and formation of the Northern Hemisphere summertime subtropical highs, J. Climate, 18, 5046-5065, 2005.

Polvani, L. M., Waugh, D. W., Correa, G. J. P., and Son, S.-W.: Stratospheric Ozone Depletion: The Main Driver of TwentiethCentury Atmospheric Circulation Changes in the Southern Hemisphere, J. Climate, 24, 795-812, 2011. 
Sausen, R., Barthel, K., and Hasselmann, K.: Coupled oceanatmosphere models with flux correction, Clim. Dynam., 2, 145163, doi:10.1007/BF01053472, 1988.

Schneider, E. K. and Watterson, I. G.: Stationary Rossby wave propagation through easterly layers, J. Atmos. Sci., 41, 2069-2083, 1984.

Shine, K. P., Cook, J., Highwood, E. J., and Joshi, M. M.: An alternative to radiative forcing for estimating the relative importance of climate change mechanisms, Geophys. Res. Lett., 30, 2047, doi:10.1029/2003GL018141, 2003.

Smith, I.: An assessment of recent trends in Australian rainfall, Aust. Meteorol. Ocean. J., 53, 163-173, 2004.

Sutton, R. T., Dong, B., and Gregory, J. M.: Land/sea warming ratio in response to climate change: IPCC AR4 model results and comparison with observations, Geophys. Res. Lett., 34, L02701, doi:10.1029/2006GL028164, 2007.

Taylor, K., Stouffer, R. J., and Meehl, G. A.: An overview of CMIP5 and the experiment design, B. Am. Meteorol. Soc., 93, 485-498, 2012.
Thompson, D. W. J. and Wallace, J. M.: Annular modes in the extratropical circulation. Part I: Month-to-Month variability, J. Climate, 13, 1000-1016, 2000.

Turner, A. G. and Annamalai, H.: Climate change and the South Asian summer monsoon, Nature Climate Change, 2, 587-595, doi:10.1038/nclimate1495, 2012.

Wardle, R. and Smith, I.: Modeled response of the Australian monsoon to changes in land surface temperatures, Geophys. Res. Lett., 31, L16205, doi:10.1029/2004GL020157, 2004.

Watterson, I. G. and Schneider, E. K.: The effect of the Hadley circulation on the meridional propagation of stationary waves, Q. J. Roy. Meteor. Soc., 113, 779-813, 1987.

Yang, G.-Y. and Slingo, J.: The Diurnal Cycle in the Tropics, Mon. Weather Rev., 129, 784-801, 2001.

Zhao, S., Li, J., and Li, Y.: Dynamics of an interhemispheric teleconnection across the critical latitude through a southerly duct during boreal winter, J. Climate, 28, 7437-7456, 2015. 